\title{
Blind Men and the Elephant ${ }^{1}$ : Implementation of a New Artifact as an Expansive Possibility
}

\begin{abstract}
:
I suggest that the transformation of an artifact from an introductory-type instrument into a viable, collectively used tool cannot be understood solely in terms of gradual adaptation of the technology and user environment, but also as a qualitatively broader integration process in which an expansion takes place. The case illustrated a constrained shift of an artifact from its first adopter, an individual pioneer user, to a more collective user in institutional medicine. The artifact, a neuromagnetometer instrument for brain research and diagnostics, brings together physicists, neuroscientists, physicians as well as various practitioners from the medical imaging industry. I applied an activity-theoretical framework for analysing the adoption of the neuromagnetometer from the pioneer phase of implementation into the more established use. The case showed that the anticipated transformation of the artifact constituted a major challenge for the user organization and its practitioners. It is suggested that an expansion of the object into a shared object of implementation among the separate practitioner groups is indispensable. This expansion of the object involves for the practitioners to recognize both the different objects and requirements of the pioneer phase of the implementation and the new phase of introduction into medical practice. It is shown that this recognition does not, however, come as given, spontaneously born in the transition. The emerging new object may remain only partially shared if not made visible by deliberate effort among the practitioners. The expansion requires collective visualization of the work and reflective dialogue on it. Employing analytical tools, such as the activity-theoretical concepts used here, is one possible way of facilitating such an effort.
\end{abstract}

\section{Introduction}

$\mathrm{H}$ ow does a community adopt an artifact? Or, the other way around, how does an artifact become part of a community and collective practice? This general theoretical question has taken various forms in empirical studies of social sciences. It has also been approached, with a more normative standpoint and practical vocabulary, in a variety of studies on management and organization. ${ }^{2}$ Has the problem been studied to closure, or is there a need for 1 "Blind Men and the Elephant" is a poem by John
Godfrey Saxe (1816-1887).

2 Introducing an innovation, a new technological artifact, into the market has been a classical problem in economical and management studies of technology and innovation (e.g., Kline \& Rosenberg, 1986; Burgelman \& Maidique, 1988; Rothwell, 1994). It has been shown in empirical studies that introduction to the market and diffusion of innovation is a non-linear, iterative and uncertain process. Classical studies in the field have identified categories of innovators, adopters and change agents as ideal-typical categories (e.g., Rogers, 1983). These analyses have focused on firm level and assumed shared values of all actors involved. Questions of learning, user-producer relations and networks have emerged in many studies during the 1990s (e.g., Lundvall, 1992; Biemans, 1992; Fleck, 1994; von Hippel \& Tyre, 1995). More recent studies have integrated ideas and methods from social constructivism and actor network theory (e.g., Coombs \& al., 1996). 
new perspectives and findings? For a student of education interested in interaction and learning taking place in the implementation of complex technological artifacts, this is a pertinent and urgent question.

The artifact studied in the present paper, a measuring instrument for brain research and diagnostics, is a transitional, hybrid artifact: in its current phase of development it brings together physicists, neuroscientists, physicians as well as various practitioners from the medical imaging industry. This artifact, a neuromagnetometer ${ }^{3}$, originating from the research on low temperature physics during the 1970s and 1980s, has been lately commercialized and introduced into hospital environment. As a new research instrument, able to provide localizing information of the brain functions, it has attracted clinical neurophysiologists and radiologists in research hospitals and has been demonstrated to be a potential clinical tool in epilepsy surgery and brain tumor surgery practices. It may constitute a new diagnostic imaging device, following the establishment of modern radiology and the integration of magnetic resonance imaging (MRI) technology to radiology practice (Blume, 1992). The question of when and in which medical practice the clinical application of the technology will become established remains open.

As a key aspect in the overall development of technology, implementation has been distinguished from technical development and installation per se (e.g., LeonardBarton \& Kraus, 1985; Fincham \& al., 1995; Voss, 1994). Implementation "involves the organization, its goals and strategies,

3 Magnetoencephalography (MEG) is the measurement of extracranial magnetic fields produced by electrical currents within the brain. Special devices are needed to measure the magnetic fields. Sensitive (superconducting quantum interference device) sensors can function only at a temperature of liquid helium (-269 Celsius). is concretely deployed." It is "the process through which technical, organizational, and financial resources are configured to provide an efficiently operating system" (Fincham \& al., 1995, 190). The interaction of various specialists, and the collaboration between organizations and sub-groups during the development and implementation of technology has been identified as a crucial precondition for deploying the artifact to practical use, constitutive to the processes of improvement, redesign, and creation of viable and commercially successful products (e.g., Shaw, 1985; Leonard, 1998; von Hippel, 1988; von Hippel, Thomke \& Sonnack, 1999), standardization of new technologies and products (e.g., Timmermans \& Berg, 1997), and market creation for new technologies and services (e.g., Green, 1992; Adler, Riggs \& Wheelwright, 1989).

What is, then, the key process underlying successful implementation, potentially leading to a breakthrough application? According to Leonard (1998, 104), mutual adaptation is the "reinvention of the technology to conform to the work environment and the simultaneous adaptation of the organization to use the new technical system" that occurs in small and large recursive spirals of change. The adaptive spirals involve both technological and organizational redesign, and vary in magnitude, depending on how fundamental is the change to be made in the implementation (ibid. p. 105). Large adaptive cycles, requiring major, qualitative changes in technology and user organizations are supposed to be of special importance for organizations facing the challenge of implementing a hybrid artifact such as the neuromagnetometer studied in the present paper. Turning the artifact to a potential new "track" in the development, in this case, from research to clinical environment, is a difficult and challenging endeavor for the organizations 
and people involved.

Fincham \& al. (1995) have pointed out that the difficulties in getting complex technologies to practical use have been long recognized, though not widely acknowledged in implementation studies. The points of view of various practitioners and occupational groups involved in the use of the new artifact are seldom distinguished, rather, "adopter organization" is typically seen as a unified entity and a target for managerial action (Voss, 1994). Studies focused on the adoption process in target organizations have directed attention to what various kinds of managers, technical specialists, trade union representatives, and others who have access to decision making, do in the adoption of new technology (e.g., Preece, 1989).

A problem not commonly addressed is the complex transformation of communities, and the integration of new practitioners and occupational groups, during the implementation of the new artifact (for an exception, see Barley, 1986, also Blume, 1992). I shall argue that there is a need for theoretical and methodological perspectives, sensitive and focused enough to capture the complex dynamics between the artifact, the communities participating in the implementation, and the various practitioners involved in the process of applying the new artifact.

The specific issue approached in the present paper is the transition of the artifact from its first adopter, an individual pioneer user, to a collective user organization. How is individual use expertise transferred into a collectively mastered expertise, and what is the significance of that transition for the innovation process? I shall suggest that this shift is critical and constitutive also to the sustainability and standardization of the new artifact.

"As a rule, one organization develops the technology and then hands it off to users, who are less technically skilled but quite knowledgeable about their own areas of application. In practice, however, the user organization is often not willing - or able - to take on responsibility for the technology at the point in its evolution at which the development group wants to hand it over. The person responsible for implementation - whether located in the developing organization, the user organization, or in some intermediary position has to design the hand-off so that it is almost invisible. That is, before the baton changes hands, the runners should have been running in parallel for a long time."

(Leonard-Barton and Kraus $(1985,103)$

This "hand-off," and the responsibility for accomplishing it within the user organization are looked at in detail in the present paper. Interesting though the suggestion about invisibility and smooth adoption is, the paper at hand provides empirical evidence which suggests that a more complex interpretation of adoption processes needs to be developed. I shall approach the problem, the challenge of transferring the artifact from its individual expert user to a user collective, by applying the activity-theoretical concept of expansion or expansive development (Engeström, 1987; 1999; 2000). I shall argue that the transformation of the artifact from an introductory-type instrument into a viable, collectively used tool can not be understood solely in terms of mutual adaptation. It also needs to be analyzed as a qualitatively broader integration process in which expansion takes - or needs to take - place.

An interest in studying a hybrid artifact, involving various heterogeneous groups, coincides with symbolic interactionist studies of science that are centered around "heterogeneous worlds coming together at work" (Clarke \& Gerson, 1990, p. 200). In scientific work, infrastructure for the specific kind of research must be created and built up to keep up with developments. Infrastructures include instruments, practices and techniques, and specific knowledge along 
mensions of potential expansion in implementation: the social-spatial ("who else should be included?"), the anticipatory-temporal ("what previous and forthcoming steps should be considered?"), the moral-ideological ("who is responsible and who decides?"), and the systemic-developmental ("how does this shape the future of the activity?") (Engeström, 2000).

I shall study a transitional situation in the implementation and use of a neuromagnetometer device at the New Mexico Institute of Neuroimaging, located at the Veterans Affairs Medical Center (VAMC) in Albuquerque, New Mexico, in the summer of 1997. This local implementation and adoption process offers a window, a laboratory setting, to highlight the complex organizational situation related to a broader transition of the innovation from basic research toward clinical use. This diffusion of innovation, and its broader professional and regulatory contexts, such as protocols of acquiring authorized approval for routine clinical use and of organizing and financing clinical experimentation, constitute another viewpoint and a research specialization which is not focused on, but indirectly referred to, in this paper.

To analyze implementation as a heterogeneous activity, I shall apply the concept of activity system (Engeström, 1987; Engeström, 1990). Activity systems are mediated by cultural tools (both material and conceptual), rules, and division of labor. The distinction between individual goal-oriented action and collective object-oriented activity is of crucial importance here. The temporal duration of actions is relatively short. Activity systems are relatively durable, historically evolving collective formations that produce individual actions and consist of members and groups (community) who share the same general object. A model of the basic structure of an activity system is nization or network) within which it takes place. Accordingly, we may identify four $d i$ - 
presented in Figure 1. The subject refers to the individual or sub-group whose agency is chosen as the point of view of the analysis.

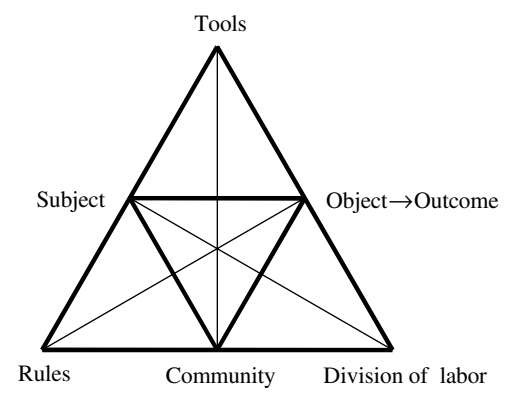

Figure 1. The mediational structure of an activity system (Engeström, 1987, p. 78)

The activity-theoretical notion of object should not be confused with the concept of goal or objective. The object is to be understood as a project under construction, moving from potential "raw material" to a meaningful shape and outcome. The motive is thus embedded in the object of activity. As organizational activity systems undergo transitions, for instance, by implementing new artifacts, they may have to redefine and expand their objects. The expansion of the object can take various forms, manifested in visions, actions and material conditions that people create during the change process. The anticipated object determines the horizon of possible individual and group actions within the collective activity. The expansion of the object eventually requires expansion in the rules, tools and division of labor - in the entire activity system.

The expansion of the object and the entire activity is not a harmonious process. Multiple historical layers and perspectives meet and interact in object construction. Implementation is multi-voiced. Activity theory regards developmentally significant contra- dictions as sources of dynamics in the implementation process. Contradictions manifest themselves in everyday breakdowns and disturbances and in participants' improvised solutions appearing in the concrete use situations of the technology (e.g., Engeström, 1996; Hasu \& Engeström, 2000; also Koschmann, Kuutti \& Hickman, 1998).

In the following, I shall first provide a brief overview of MEG and its transition to clinical use at the time of the research period 1996-97. I will then introduce the setting, the New Mexico Institute of Neuroimaging, and the data analyzed in this paper. I shall briefly describe the background of the specific transition process going on at New Mexico Institute of Neuroimaging in the summer of 1997, and proceed to analyze the perceptions of the four main groups of practitioners involved in the use of the neuromagnetometer device concerning the process of implementing the device in clinical use. I shall analyze the perceptions along the four dimensions of expansion of activity introduced above. Finally, I shall discuss my findings and their theoretical and practical implications.

\section{Implementing magnetic source imaging technology to medical practice}

\section{The MEG innovation and its use in tran- sition}

The development of the neuromagnetometer (MEG) device is an example of a sciencebased innovation which have had a long technical development process in university context before adoption to practical use (del Campo \& al., 1999). In the early 1970 s, a few research groups at university physics laboratories, for instance, in the Helsinki 
This work was boosted by the companies because they anticipated opening the clinical market for MEG devices. However, the anticipated breakthrough in clinical applications was still to come in 1996-1997, at the time of the data collection for the present study. Within this period, the organization studied in this paper, the New Mexico Institute of Neuroimaging, was the most advanced user organization among the Finnish manufacturer's customers in practical clinical work.

The technical development of MEG is not, as such, at the core of the present analysis. Rather, the attempts of the manufacturers and the key user organizations to develop the MEG technology from a research instrument into an established medical device are looked at from the point of view of one user organization in its early phase of adopting MEG to medical practice. It should be noted here that the transition of the artifact and the transition of the user organization are different processes with different dynamics, which, however, have certain crucial interrelations. The users' significant role in redeveloping and designing artifacts has been recognized, for instance, in the development of scientific instruments and medical devices (von Hippel, 1988; Shaw, 1985; 1994). Manufacturers are dependent on lead users and pioneer groups willing to apply the often unfinished artifact and codevelop it with the developers. To illustrate this multi-faceted and multi-layered character of adoption, I shall now turn to the transition of the user organization. 1990s, several new MEG systems were installed in research institutes and university hospitals, and preliminary work with potential clinical applications was conducted by pioneer groups in the US and in Finland.

4 The early development of MEG in Finland is described in Hasu (1999) and Hasu \& Engeström, (2000).

\section{The New Mexico Institute of \\ Neuroimaging: Data and setting}

The data of the present study was collected during a six-week intense field work period at the neuroimaging laboratory, the New Mexico Institute of Neuroimaging (NMIN), in the summer of 1997 when it was facing 
organizational changes after a period of rapid growth. The primary data consist of interviews with personnel of the NMIN working with MEG and referring physicians at the local hospitals. In addition, ethnographic observations of laboratory work as well as the videorecorded meetings and use situations of the multi-modality imaging technologies are used as data. The occupational groups analyzed in this paper and involved in the use of MEG and its application, Magnetic Source Imaging (MSI), are presented in Table 1.

\begin{tabular}{|l|l|c|l|l|}
\hline $\begin{array}{l}\text { Practitioner Group } \\
\text { (No. of interviews) }\end{array}$ & $\begin{array}{c}\text { Number of } \\
\text { Practitioners }\end{array}$ & $\begin{array}{c}\text { Organi- } \\
\text { zation }\end{array}$ & Educational Background & Work Tasks/ Description \\
\hline $\begin{array}{l}\text { Technologists } \\
(3)\end{array}$ & 3 technologists & NMIN & $\begin{array}{l}\text { Registered radiology } \\
\text { technologists }\end{array}$ & Operating the MEG system \\
\hline $\begin{array}{l}\text { Scientists } \\
(3)^{5}\end{array}$ & MEG scientist & NMIN & Neuroscientist (Ph.D.) & MEG data analysis \\
\cline { 2 - 5 } & MRI scientist & NMIN & Neuroscientist (Ph.D.) & MEG/MRI data integration \\
\hline \multirow{2}{*}{$\begin{array}{l}\text { Intraoperative } \\
\text { team } \\
(2)\end{array}$} & MEG/MSI nurse & NMIN & Bachelor's D. in Nursing Patient care \\
\cline { 2 - 5 } & $\begin{array}{c}\text { Intraoperative } \\
\text { technician }\end{array}$ & NMIN & $\begin{array}{l}\text { Technician's experience } \\
\text { in US army }\end{array}$ & $\begin{array}{l}\text { Operating the intraopera- } \\
\text { tive system in operation } \\
\text { room (technician and } \\
\text { nurse) }\end{array}$ \\
\hline \multirow{2}{*}{$\begin{array}{l}\text { Clinicians } \\
(4)\end{array}$} & $\begin{array}{l}2 \text { neurologists } \\
\text { Nom }\end{array}$ & $\begin{array}{l}\text { UNM } \\
\text { Hospital }\end{array}$ & $\begin{array}{l}\text { Specialized in Clinical } \\
\text { Neurophysiology }\end{array}$ & $\begin{array}{l}\text { Electrocorticography and } \\
\text { electrical stimulation in } \\
\text { operation room }\end{array}$ \\
\cline { 2 - 5 } & Surgeon pool & $\begin{array}{l}\text { VA, UNM } \\
\text { Hospitals }\end{array}$ & $\begin{array}{l}\text { Specialized in } \\
\text { Neurosurgery }\end{array}$ & $\begin{array}{l}\text { Operating the patient in } \\
\text { operation room }\end{array}$ \\
\hline
\end{tabular}

MSI=magnetic source imaging, MEG= MEG system (magnetoencephalography technology), MRI= magnetic resonance imaging, NMIN=New Mexico Institute of Neuroimaging at VA, $\mathrm{VA}=$ Veterans Affairs Hospital, UNM=University of New Mexico

\section{Table 1. Practitioner groups involved in applying MEG at the Institute in 1997}

The New Mexico Institute of Neuroimaging (hereafter only the Institute) at the Veterans Affairs New Mexico Regional Federal Medical Center in Albuquerque, USA, is a separate, private neuroimaging center housed in a government-owned hospital. Its main

5 The interview with the former principal MEG scientist of the Institute is included. goal is to "assist neurologists, neurosurgeons, and psychiatrists in the diagnosis and treatment of disease through applications of advanced technology and the development of new imaging modalities." Through sharing agreements with the University of New Mexico and other local hospitals, the Institute provides neuroimaging studies for patients from the local community, the federal, state, and private sectors. In 1996, there 
were seven diagnostic neuroimaging programs at the Institute with more than 20 modalities, one of them the magnetoencephalography (MEG) technology and the magnetic source imaging (MSI) method used in the localization and imaging of the functional regions of the brain.

The main clinical application of MEG used currently at the Institute was the mapping of the functional areas of the brain, that is, the localization of somatosensory, motor, visual, auditory etc. regions for preoperative planning in neurosurgical operations. The use of MSI for neurosurgery involves the integration of the functional MEG data with the structural data from the magnetic resonance imaging (MRI) modality to produce magnetic source localization images that show the precise inter-relationship between the brain function and the structure. As a concrete example of emerging clinical use, the process of applying MSI in neurosurgery practice was discussed in most interviews. An overview of the work process of applying MSI in brain tumor surgery is presented in Figure 2. It depicts the work process as an anticipated, ideal model of the emerging clinical service with MEG at the Institute. Figure 2 aims to illuminate the two crucial challenges of the implementation of the new artifact within the established hospital settings: integration of several new and already standardized technologies, and integration of various occupational groups into a collective practice.

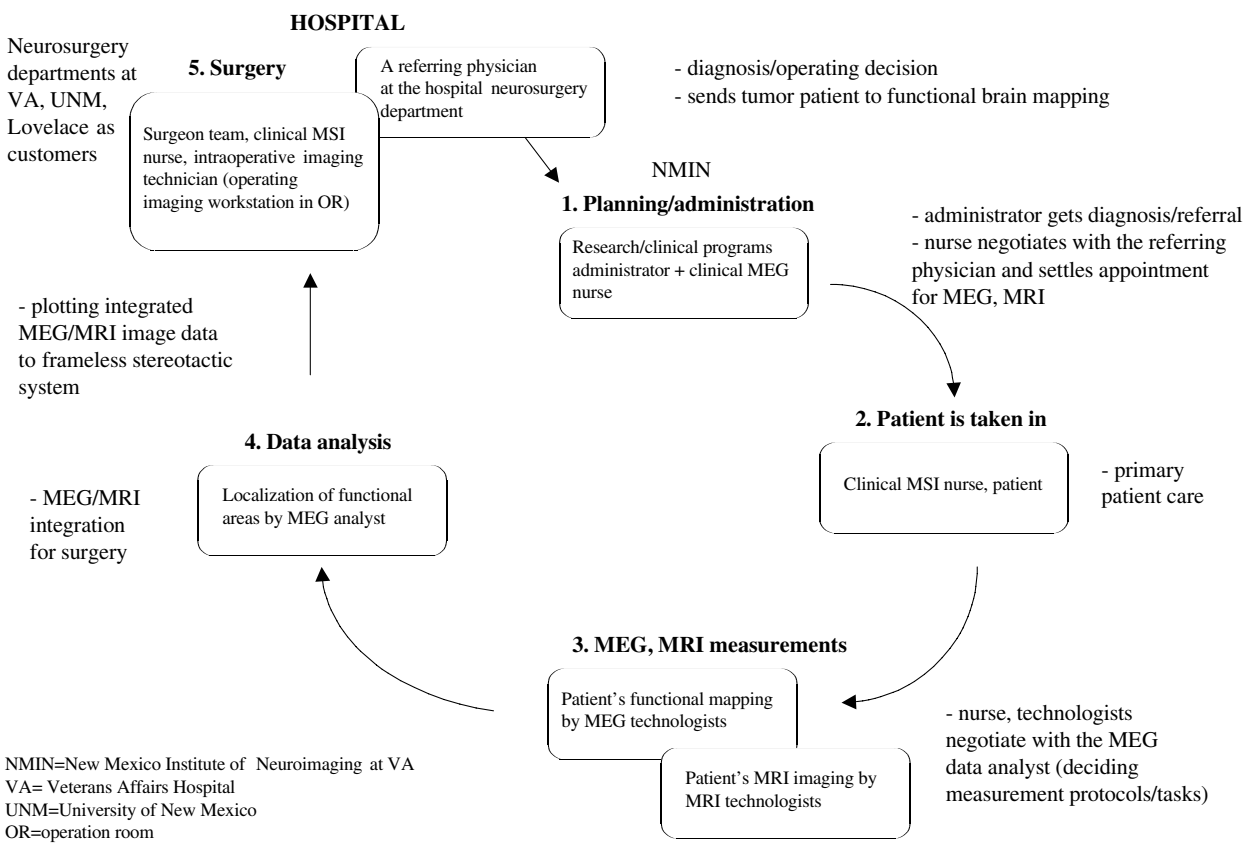

Figure 2. The clinical work process of applying MEG (MSI) in brain tumor surgery at the Institute in 1997 (an ideal model)

The applying of MSI involves four major steps prior to the actual use at the operation room in the hospital neurosurgery department. (1) The referral of a surgical candidate for functional brain mapping comes from a hospital physician (typically from a neurosurgeon), and the Institute's administrator together with the MEG nurse set the MEG 
and MRI measurement appointments for the patient. (2) The patient is taken in to the Institute and prepared for the measurements. Within these phases, the MEG nurse may negotiate with the referring doctor about the MEG measurement protocol to be used in the particular case. (3) The MEG measurement and the MRI imaging are performed with the patient. (4) The MEG data are analyzed and integrated with the MRI images of the patient. These work actions at the Institute were largely invisible for the referring physicians. Finally, if the neurosurgeon still decides to operate on the patient, the localizing information is used for planning the surgical approach, and taken to the operation room by plotting it in the imaging workstation (frameless stereotactic system). Depending on the urgency of the surgical case, the entire process may be performed within a week.

At the Institute, the practitioners involved in the use of MEG were located in the same area with the practitioners working with the other imaging modalities. For instance, the MEG technologists worked close together with the MRI technologists in a small measurement area devoted to the operation of both MEG system and the MRI system. The patient care related to the measurements took place in this area as well. The scientists had their separate office near the measurement area. The MEG nurse and the intraoperative technician also stayed in a separate office when preparing the imaging workstation for the operation. A partial layout of the Institute with locations of the MEG practitioners is presented in Figure 3.

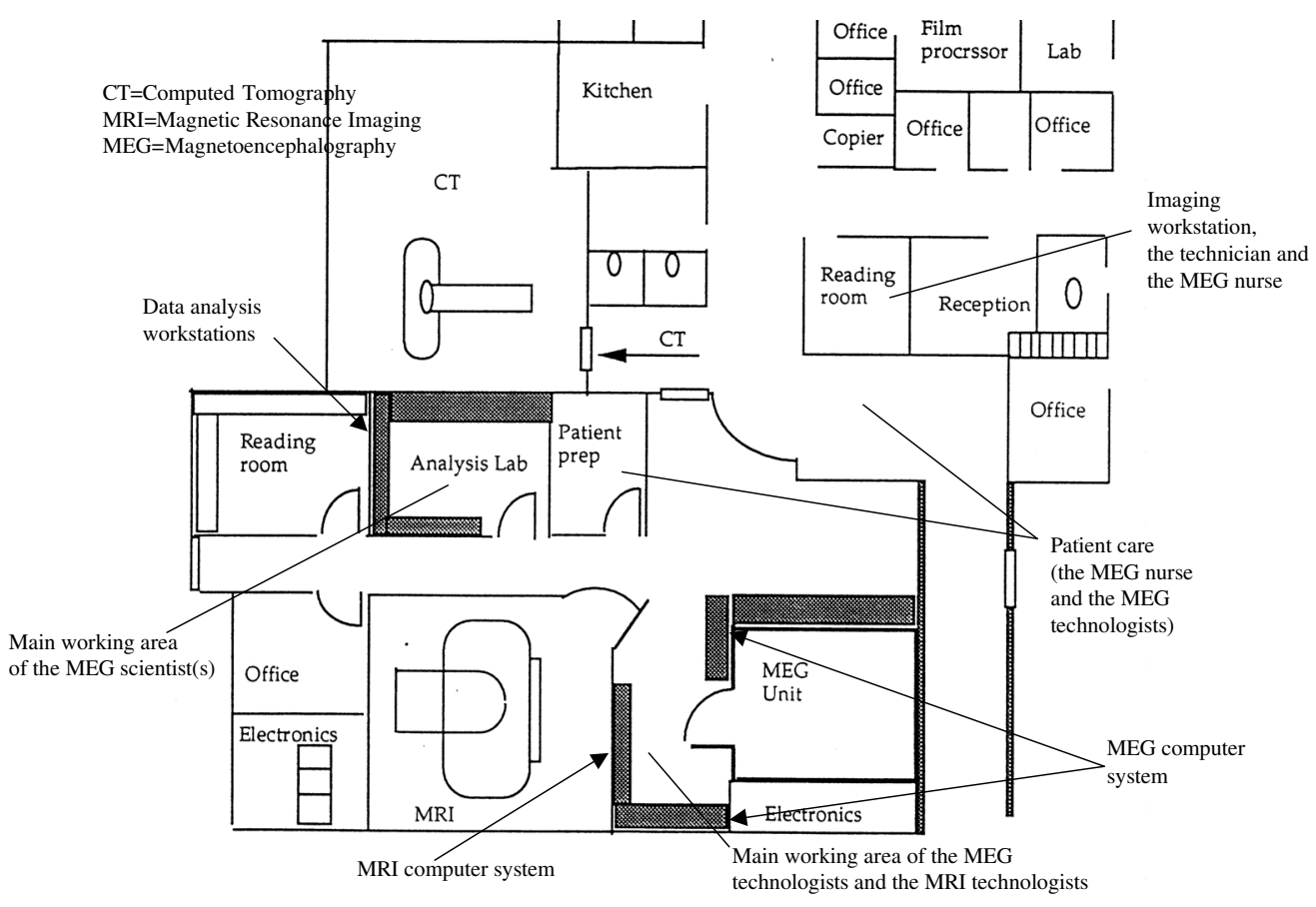

Figure 3. Partial layout of the Institute: Locations of MEG activities and practitioners and MRI and computed tomography $(C T)$ areas 
ing facility, and the MEG program was expanded to cover a wide variety of studies with various patient groups. Together with a new principal scientist hired to run the MEG program, the director of the Institute built an efficient model of producing MEG measurements in the fashion that hospital laboratory protocols typically require: efficiently, quickly and with proper patient care. To a large extent, the model followed the way the MRI images are produced: for instance, MRI technologists were trained to operate the MEG system and perform measurements with it.

\begin{abstract}
One goal was just to get a survey of what MEG might be able to see, a wide variety of patients, and also to show that if you do run large numbers of patients, MEG can be used in a kind of mass production way (...) the same way MRI is: you get someone in, you do the test, you analyze it, and you do two or three a day. (...) (Interview with researcher D.J., a neuroscientist, June 6)
\end{abstract}

The phase of intense development in applying MEG at the Institute is depicted in Figure 4. During this growing phase, in 1993-1996, the principal neuroscientist, without any previous experience in MEG, took charge of the MEG program and became a pioneer in applying, analyzing and interpreting MEG data for clinical purposes. He started, together with the facility director mentioned above and a few neurosurgeons from the local hospitals, applying functional brain mapping in preoperative planning of brain tumor patients. Toward the end of this period, the supplier of the MEG system changed, and a Finnish company, Neuromag, supplied the first whole-head MEG system to the Institute.
Under radiology specialty, the Institute was developed as a multi-modality neuroimag- 
outlines-2000.qxd 23-11-00 12:55 Side 15

TOOLS:

MEG system(s)/Magnetic

Source Imaging (MSI)

MRI system

SUBJECT:

Frameless stereotactic system

Senior neuroradiologist (facility director), neuroscientist (principal scientist), MEG technologists

\section{RULES:}

Contract with the vendor firm: show-site status Radiology dominated culture in applying technology

A single pioneer user: unlimited working hours in applying MEG
OUTCOME:

Major amount of

patient measurements

(Experimental) use of MSI

in neurosurgery

A few published "patient case histories"

Figure 4. The phase of growth at the Institute in 1993-1996, modeled as an activity system

During this period, the Institute produced a major amount of patient measurements but a limited number of scientific publications for securing independent research funding. From the founding of the Institute in 1993 to 1997, patient examinations included more than $20000 \mathrm{MRI}$ and CT studies as well as over 1300 clinical functional brain imaging (MSI) studies. Since the installation of the new whole-head MEG system in 1994 to 1997, 38 neurosurgical patients with brain tumors and over 120 epilepsy patients had been evaluated at the Institute. The evaluation of the clinical applications for Federal Drug Administration Office (FDA) approval had been done previously for the old MEG system, but was yet to be done for the new system. The Institute was now facing a more intense challenge of validating and sustaining the new system in clinical work, and also of reporting the findings to the scientific community.

The main application of MEG, the implementation of MSI in preoperative planning of neurosurgical patients, was still in its early stages in 1997 as the organizational situation at the Institute changed dramatically. At the beginning of a new phase at the Institute, challenged to move from the introduction of clinical application to the adoption and consolidation, the facility director together with the principal MEG scientist left the Institute to open a new neuroimaging Center in another state in the USA. Part of the MEG operating staff left the facility as well to join the new Center. At the same time, a few key collaborators and customers, for instance, two neurosurgeons involved in using functional brain mapping, left the surrounding hospitals. In addition, the Institute 
From an activity-theoretical perspective, lost the show-site status and the additional funding connected to it, due to the newly established Center being now more attractive for the supplier firm's customers. These critical organizational changes and the simultaneous challenge of sustaining the use of MEG in neurosurgical practice comprise the Institute's transition examined in this paper.

\section{Perceptions about the transitions going on at the Institute}

I $\mathrm{n}$ the following section, I shall examine how the various practitioners involved in the clinical use of MEG perceived ${ }^{6}$ the transition at the Institute and in the broader network. One might assume that perceptions about such a dramatic change would be homogenous, one-sided and linear, obviously emphasizing "the good old days" in this case. It will be shown in the following that this was not the case - or the whole picture (for similar findings, see also Blackler, Crump \& McDonald, 1999).

How does the interview data reflect and illustrate the complexity of the current transition at the Institute? In particular, are there any indications about changing objects of the implementation process of MEG? In what way do perceptions highlight the anticipated overall challenge of the innovation process, the introduction and standardization of MEG to clinical use?

\footnotetext{
6 The notion of perception used here is related to the notion of conception widely used in phenomenographic studies of the different understandings of phenomena in the world around us. The various understandings, conceptions, are seen as experiential relations between the individual and the phenomenon (Marton, 1981). However, I did not apply the phenomenographical strategy in which a conception is categorized and abstracted from the expressions that are considered to reflect it. My interest was to capture the variety and situatedness of the ways in which the interviewees talked about the transition.
} implementation of new artifacts can be regarded as reconstruction and redefinition of the object of activity, in and through specific situated actions. As organizational activity systems and their fields undergo transformations, they often redefine and expand their objects. The dimensions of expansion discussed above become salient in problem situations and periods of intense change (Engeström, R. Engeström \& Vähäaho, 1999; Hasu, 2000).

In order to trace indications of change and potential expansions of the object of the practitioners, I analyzed the interview data in the framework of the four dimensions of expansion described in the introduction. For the present analysis, I reformulated the criteria presented by Engeström (2000) in three ways. First, I included in the social-spatial dimension also indications of physical-spatial expansion, that is, other technical artifacts and systems ("who else should be included, and what other artifacts/systems should be considered?"). Second, in the anticipatory-temporal dimension, I included perceptions that indicated not only anticipated steps but also directions of possible new approaches and foci of work ("what previous and forthcoming steps, and potential new directions and approaches should be considered?"). Third, in the systemic-developmental dimension, I included perceptions that emphasized the developmental aspect of artifacts ("how does this shape the future of the activity, and how the artifacts used in that activity should be developed or transformed?").

When transitioning from the early startup phase of the implementation toward the phase of adoption and consolidation, expansion of the object along the social-spatial dimension would typically imply that instead of being regarded as an independent, isolated piece of technology (or operation), the 
outlines-2000.qxd 23-11-00 12:55 side 17

artifact is constructed in its use contexts. That includes other artifacts as well as various organizational relations. The anticipatory-temporal expansion would mean that instead of being seen as a discrete, one-time project or endeavor, the implementation is constructed as a continuous, iterative process involving various phases and levels of activity. Moral-ideological expansion would mean that instead of each individual user/ applier being responsible just for a specific work task within implementation, all practitioners involved take responsibility for the entire implementation and adoption trajectory. This implies also a reconsideration of power relations: it is no longer automatically given that the highest ranking specialist or the most experienced, advanced practitioner alone has absolute power and responsibility to determine the course of the implementation and adoption. The systemic-developmental expansion would mean that instead of actions being seen only as influencing the given local context of implementation, they are also seen as shaping the broader development of the technology and its adopter practices.

Clearly articulated expansions may not be the only way of dealing with transition and change. Transition is contradictory, and the anticipated expansions may collide with conditions that keep remaining the same in a given organization. I assume that there are not only clear-cut, concise perceptions about transition, but also - in the form of dilemmatic speech (Billig \& al., 1988) - unclear, emerging attempts to make sense of the past and of what is presently going on.

I included in the analysis the interviews of those participants who had been involved in the implementation and clinical use of MEG for over one year. The collaborating clinicians such as, for instance, the main neurosurgeon and the main collaborating neurologist from the UNM hospital, did not present interpretations about inner work dynamics or specific division of labor of the Institute. Each clinician had been identified as a possible collaborator by the former leaders ("They identified me as someone who might be interested in MEG") and each clinician co-operated with the Institute individually. For them, transition meant only a change in directorship that had "not changed the affiliation" of co-operation. They were doing "their part of the deal" with MEG people and their main interests were focused on their own medical practice such as treatment of epilepsy patients or neurosurgical patients, or their own individual research projects. In a way, they looked at MEG from a distance: they seemed to be interested but not deeply involved in it.

Respectively, the technologists responsible for the operation of the MEG system and measurements at the Institute mainly dealt with problems and challenges pertaining to the operation of the system and also to the division of labor and collaboration on the organizational level. They had only seldom communicated with the clinicians and had not even once visited the operation room to see how MSI results were being used. Although expressing concerns and worries about the future development of MEG at the Institute and about their own work situation, they had a positive and hopeful perception about the direction of transition that they assumed to be happening. They also expressed their feelings about the preceding phase and the Institute's people ("I hope we can divorce ourselves from N.N.").

To a large extent, the neuroscientists dealt with the organizational context and the broader network. The MEG scientist currently responsible for data analysis did cooperate with some of the hospital clinicians but he had not visited the operation room when MSI results had been applied. The former principal MEG scientist, together with 
gists and the scientists did not, for instance, take their lunch or coffee breaks together. The MSI nurse and the imaging technician, working together on the preparation and display of images for surgery, also formed a separate team shuttling between the Institute and the surgery departments. They also had their lunch and did sports together. The nurse worked also in the measurement area taking care of surgical candidates coming in for MEG and MRI scanning, and when there was a need, for instance, to sedate child patients.

A few individual practitioners seemed to be affected more than others by the organizational changes of the Institute taking place simultaneously with the transition to the adoption and consolidation phase of applying MEG. One of them was the MEG scientist responsible for clinical data analysis and interpretation. Also the MSI nurse and the imaging technician, as well as the principal technologist responsible for the MEG system were deeply engaged in the ongoing transition.

Especially two of the four dimensions of expansion, the anticipatory-temporal and the moral-ideological dimension, proved to be illuminating when applied to the interview data. Perceptions about transition categorized with the help of these dimensions indicated emerging changes in the object of implementation. Among all practitioner groups and along all four dimensions of expansion, especially one concern continued showing up in the data. That was the constraint of isolated individual expertise and responsibility in applying MEG, with a simultaneous challenge of sustaining MEG in clinical use. I shall examine in more detail how these concerns emerged within the four dimensions and how they reflected the present challenges of sustainability and standardization of MEG. 


\section{Social-spatial dimension}

$\checkmark$ xpansion along the social-spatial dimension of the object can best be illustrated in the situation of the MEG technologists. The desired expansion of the work object, participation in data analysis, was expressed by all the three technologists. They mentioned having their measurement work temporarily scaled down since the departure of the former facility director and principal MEG investigator. This can also be seen in the laboratory log as there was a period of a few days without any measurements at all. There seemed to be a natural motive to find something to do on such days. In addition, data reading had become a veritable bottleneck, as there was only one scientist engaged in it.

The principal MEG technologist came to associate the separated work on measurements and the spatial layout of the laboratory with what prevented encounters between the technologists operating the MEG system, on the one hand, and the scientists doing the data reading, on the other. The principal technologist related the importance of information about the quality of the measurement event to the quality of the data analysis. As a supervisor of his colleagues who were engaged in the actual patient measurements, he had a perspective both on data collection (in measurement area) and on data review (taking place in the analysis laboratory) prior to actual analysis and interpretation done by the MEG scientist.

\section{Excerpt 1}

Interviewer: Do you like it [division of labor in producing MSI results] this way? Are you, in a way, content with this division of activities?

Technologist 1: I think the layout of the site could be a little different. Having a divided area between where the data is collected and the data is analyzed is actually a weakness, because it tends to separate the group a little bit, and I think it's a good collective force to stay together all the time. I'd like to be around hearing more of the data analysis discussion. I've overheard discussion that gets created on the data analysis side, and I've overheard discussion that gets created on the scanning side, that is contrived and is sometimes not true. (...) For example, I've heard where a data set gets reviewed and I just cannot explain why for example a particular dipole seems to be in the wrong place, and... well, the patient must have moved, and there was never an attempt to follow up and see if this really happened...

Excerpt 1, centering around a wish to "be around hearing more of the data analysis discussion," indicates also responsibility over the boundary between the two functional work tasks, the data gathering and the data analysis. It highlights the expansion of object from merely performing measurements toward concern over each data production and analysis cycle. The systemic conditions of the MEG technologists' transitional situation may be summarized with the help of Figure 5 , depicting contradictions of the activity system of the technologists participating in the application of MEG. The expansive perspective is explicit in the object, outcome, community and division of labor in Figure 5.

However, the expansion of technologists' work to include data analysis is inherently contradictory. The present state of data analysis and clinical interpretation still required, as one scientist stated, "too much subjective interpretation," being a process of several years' apprenticeship learning for the few neuroscientists engaged in it. Also the rules concerning payroll and work time among technologists and scientists were different. Much of the data reading was done late in the evenings. For the technologists to engage in data analysis work with routine radiology experience and regular office hours was problematic, to say the least. The lightning-shaped two-headed arrows between the tools and the object, and between the rules and the object in Figure 5 indicate these contradictions. 
TOOLS:

MEG system

System software

Expertise with routine

radiology

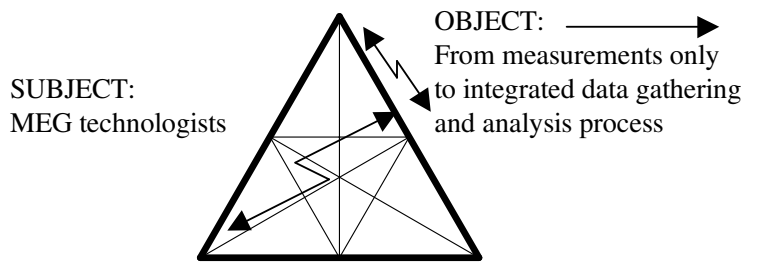

OUTCOME:

From measurement under control to integrated data gathering and analysis process under control

RULES:

Regular office hours of the technologists Flexible working time of the analysts (working late in the evenings)

\section{COMMUNITY:}

From MEG technologists only to technologists

and scientists (analysts) together
DIVISION OF LABOR:

From measurement work and data analysis work

treated separately and located in separate spaces to both integrated and located in the same space

Figure 5. Systemic conditions of transitional situation for MEG technologists at the Institute in 1997

The MRI scientist touched upon a possible resolution to these contradictions as he stressed the possibility to reduce the level of subjective training and experience by developing new analysis software. He did not see the long "learning curve" for analysis work as an obligatory passage point, an inevitable rule, in the implementation and adoption of MEG.

\section{Excerpt 2}

One of the big problems (...) is the way the technology is currently implemented, in that it requires a lot of subjective interpretation, and I really think the analysis processing and the response identification is gonna be really improved algorithmically to reduce the level of subjective training and experience that is required. I think the current way it's implemented really puts an unnecessary emphasis on a lot of experience in reading these types of things where... I think it can be done better, so that you don't have to have such a long learning curve to get up. (...) There's certainly lots of opportunity for automation and the data analysis and data preprocessing - even in the supervised sense - it doesn't have to be totally automatic, we just... a way of helping manage the complexity. (Scientist 2)
Integration of technologies as a central precondition in the implementation of MEG was also taken up in the interviews. Application and use of multi-modality imaging was part of the mission and also an area of expertise of the Institute. The history of MEG at the Institute consists largely of development and application of data interchange, integration and display between the MEG and MRI systems. Display of integrated images and their use for image-guided surgery in the operation room had required adoption of special systems, e.g., frameless stereotactic workstation, which was in a developmental phase and being tested at the Institute. This work had started at the Institute already in the 1980s before the Dicom data interchange (transfer) protocol became standard in the systems.

For a collaborating clinician who had followed the MEG work at the Institute ever since its inception, the starting point for any communication about the possibilities of MEG in the radiology community was the 
outlines-2000.qxd 23-11-00 12:55 Side 21

OUTLINES • 2000

image: functional location provided by MEG as related to the anatomy of the brain.

\section{Excerpt 3}

(...) even though radiologists have more physics because of the x-rays - nothing close to MEG - and even though they were located here, you don't see a radiologist come near, except occasionally someone like L.R and O.B. A majority of them don't wanna even come near this place, because it's so weird. To a radiologist the picture is everything. So, if we didn't come up with putting the location on to the MRI, we would've gotten nowhere. (Clinician 2)

According to an MRI scientist, an architect of technology integration at the Institute, the ongoing challenges included automated data analysis processing (e.g., development and acquisition of improved analysis software) on the side of data production, and display and use of the data (e.g., development and use of imaging workstation and software) for surgical operations. Accuracy of the process was still a major ongoing concern. A picture of implementing the technology locally as a continuous process of including and improving artifacts and their use practices emerged in the interview. Improvement of artifacts and processes will need development work both in the local setting and among technology suppliers.

\section{Excerpt 4}

There are a couple of questions that are interrelated: certainly there's a big issue on the display and use of the data. How to properly display the results for referring physicians and, and how to use the results in our surgical systems are an ongoing issue, how best to represent the values that are provided, and I think that there's quite a lot of room for improvement on that given the current practices. The other main issue that I see is one of accuracy of the process, and issues that are doubt with anybody who works with multiple data sets or physical patient (...) How to quantify the accuracy and present that accuracy to the users. (...) Currently (...) there's no assessment of anything of the uncertainty of that location, which I think is very important for physicians' interpreta- tion. So, those are the two general categories that I think are ongoing and still should be. (Scientist 2)

As excerpt 4 illustrates, implementation of new technology and its application is seen as an ongoing, mundane problem solving process with continuous improvement of various technical systems and their combinations.

These findings are in line with the socialspatial dimension of expansion discussed in section 4. In addition to social relations, practitioners expressed a need to expand the object of implementation spatially and physically. The MEG technologists desired to enlarge their work description and become included in the data analysis work which had become a veritable bottleneck at the Institute. Continuous improvement of artifacts and systems was expanded to cover also the improvement of practices of using those systems. This idea of continuity and mundane, iterative work in integrating and improving artifacts and use practices implies also the anticipatory-temporal expansion of the object among the practitioners.

\section{Anticipatory-temporal dimension}

I nterestingly enough, perceptions about the preceding focus of the Institute varied among the interviewed. The idea about the priority of the Institute in some cases varied or contradicted even among an individual practitioner. For the technologists, the former focus of the Institute was neuroscience: "developing neuroscience program as opposed to a clinical MEG program" (technologist 1) or "program has been oriented around neuropsychology at the expense of clinical program" (technologist 3). On the other hand, the way that "doing science" appeared to the technologists seemed to contradict the typical notion held about 
science ("we never ... do the very basics", technologist 2). That the priorities of the Institute were somewhat unclear or dilemmatic for the technologists, supports the finding of a discrete character of their work discussed above. It can also indicate the multiple - and potentially contradictory objects of the Institute not clearly articulated and made visible among the various groups of the organization.

The excerpt below illustrates the expansion of a technologist's object along the anticipatory-temporal dimension. The anticipated work objective will no longer be an isolated measurement operation, but, instead, the re-examining of the entire process from measurement to utilization of the results. This is also seen as a collective effort (recall the expression "as a group" occurring twice in the excerpt 5). It implicitly presupposes continuity, that is, a project or a developmental trajectory set up jointly. Reduction of the personnel time used in the process is connected to the reduction of costs of the service, enhancing the availability of service for patients and their insurance companies.

\section{Excerpt 5}

Interviewer: What will be the main focus in the near future - in your opinion?

Technologist 1: What I believe we need to do right now as a group, is to closely examine all the steps of the process, and then as a group decide, with input from the clinicians, what we really need to answer for them... and that's where I believe we're heading right now... (...) I think it's getting - this machine on a track of a clinical program so that the exam could be done in a timely fashion. The expense of MEG right now to the patient is very high, because of the time involved in data collecting and then even more specifically, the analysis time. If we can reduce the cost to the patient, that will be beneficial to the patient, the insurance company, and the only way we can reduce the cost is to spend less personnel time on this process.
For the neuroscientists working full-time at the Institute, the past work at the Institute centered around the notions of "mass production" and "bootstrap mode". The anticipated work approach needed to be moving toward a more "long-term scientific approach" and "scientific rigor". Still, the past approach was not seen as merely negative: it was seen as an indispensable phase of development, a necessity "to get it going". They addressed the present need to identify or re-direct the guiding research problems in order to produce publishable results. To achieve this kind of goals would require an "ongoing program of investigation," that is, expansion of temporal dimension of the object from short-term, preliminary studies toward long-term, hypothesis-driven investigation.

\section{Excerpt 6}

Clearly Doctor O.B. did an amazing job of bootstrapping this place and getting it going, and that was based on an approach to technology and how you sell it and push it forward. The facility, though, has also matured quite a lot - instead of being in a bootstrap mode we are at an operational mode, and transition makes it extremely useful that we've had a difference in directorship at the facility. And that has allowed us to move from fairly early preliminary introduction type of work to an ongoing program of investigation that has scientific rigor. (Scientist 2)

The physician-researcher who had followed the MEG work at the Institute since its beginning advocated connecting the Institute's future approach to already existing approaches and research questions in the field as a prerequisite for research collaboration between sites.

\section{Excerpt 7}

We sort of have to start and get a scientific footing. Working under doctor O.B's regime, we produced a lot of work and limited publications. I don't necessarily say we're alone - but that winds up in some 
outlines-2000. qxd 23-11-00 12:55 Side 23

funny ways slowing down the credibility of a field. Doctor L.R., he comes out of a Ph.D. type background, he is very much of a hypothesis-driven scientist, and I think clearly intends to change how we do business here. So, we will be parallel with the Finland group and other groups. That makes it a lot easier for collaborations to occur, because you're doing the same types of things. Once you've agreed upon a same study protocol, you both can do it. (Clinician 2)

The tension-laden and in various ways contradictory situation related to the anticipatory-temporal expansion of object is perhaps best illuminated in an interview with the neuroscientist currently responsible for MEG data reading. He had been deeply involved in the preceding era of the MEG work at the Institute, being trained as a data analyst by the principal MEG scientist who had now left the facility. He was literally living between two worlds and seemed to vacillate between which one to step in. On the other hand, he did see the dilemmas of the former approach: not enough specific focus, not enough publications to attract independent research funding.

\section{Excerpt 8}

Interviewer: How would you describe the transition process you are living through at the Institute with MEG right now?

Scientist 1: First, I have to say something about what happened before they [the former facility director and principal MEG scientist] left, so you can understand what we're transitioning from. So... Doctor O.B.'s goal was to run as many patients of every kind as possible, and in the process succeeded two things. (...) First of all, we had a lot of case histories that were very interesting that showed the value of MEG. We did show that MEG could be used on a very rapid turnaround basis. It also made a number of people unhappy in that the workload didn't allow us to turn out papers, and, they felt like research was probably the primary thing that we should be doing.
And also it didn't allow us to focus on any specific issues. (...). So when Doctor L.R. came in, they decided to have strict criteria for specific studies, and have some of them be clinical studies and some of them basic science studies, but in any case, whatever kind of study it was, there would be two kinds of patients or subjects: there would be those patients for whom there's an already defined value for the use of MEG, like tumor patients... All the other categories of patients are more under clinical research in that we need to find out what we can do for these kinds of patients.

The ongoing transitions had made the already laborious work with data reading even more intense for the scientist, as he was the only one doing clinical interpretation of data at the site. He was stressed out, and he told that he was coping on a day to day basis, unable to think of the whole process, or how to improve the way things were. He had also started to consider joining the group that had left the site.

\section{Excerpt 9}

Interviewer: What is your special area now here in this Institute?

Scientist 1: (laughs) I would say I'm on everybody's area right now. I am involved in virtually every study that involves the MEG. By necessity I become involved in it. And since I'm involved in everyone of those and do the clinical reading... So, if it's a clinical analysis, I do probably 99 per cent of that. I should be doing other reading as well, for research. I don't actually end up doing those analyses, because I just don't have the time.

Given that the neuroscientist's time was completely consumed in clinical reading, the anticipated expansion of object involving a long-term, hypothesis-driven research and publishing was inherently contradictory for him. The systemic conditions of the MEG scientist's transitional situation may be summarized with the help of figure 6 . 
TOOLS:

MEG system (MSI), MRI system

Data analysis/interchange programs

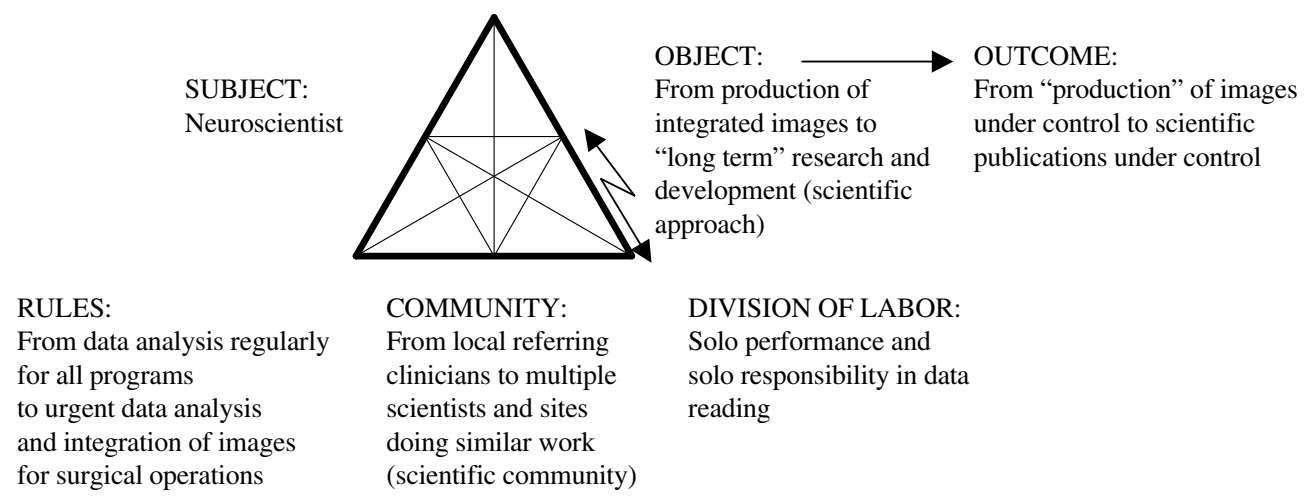

Figure 6. Systemic conditions of the transitional situation for the MEG scientist responsible for data reading at the Institute in 1997

In the course of the interview, the scientist touched several times upon the dilemma of combining research work and applied work with scarce resources and personnel. The same constraint appeared also in the interview of the neuroscientist formerly responsible for the MEG program at the Institute. He had at first done all the data reading by himself, working hundred-hour weeks demonstrating MSI to neurosurgeons. Now the same situation was reoccurring. A contradiction emerged between the anticipated object of long-term research and the division of labor based on solo performance and solo expertise in data analysis. The lightning-shaped two-headed arrow in Figure 6 depicts this crucial tension. Still, research was supposed to be the future focus of the Institute.

\section{Excerpt 10}

Interviewer: And what do you think, has the focus of work changed, or will it change now when the new facility director has started?

Scientist 1: So, his [Director's] approach to getting support and to becoming a major site is to develop research work. That's gonna take a long-term commitment, it needs people who, who do research... Interviewer: Has he said it?

Scientist 1: Yeah, he has. He's... stated this as a... as a plan. His goal is to develop basic and clinical research at this site. And, the problems with that are what I just discussed... that nobody has time to actually do that research.

Although the idea about the past era of the Institute varied among the interviewees, most of the practitioners clearly advocated transition at the Institute - changes in the priorities of work, more scientific focus, and more long-term approach concerning the development and applying of MEG. These findings indicate anticipatory-temporal expansion in the object of implementation that is in line with the Institute's emerging challenge of moving from the introductory phase of the implementation toward establishing the use of MEG in the local community. However, this expansion turned out to be constrained and problematic. The desired anticipatory-temporal expansion did not 
correspond with the prevailing division of labor and resources at the Institute, causing solo performance and solo expertise to continue in the data analysis. Development of more collectively mastered expertise and standardized tools in the analysis and clinical interpretation can be seen as critical and constitutive to long-term success of the transition. Current challenge of the transition may require - as a first step - exploring the common ground for MEG work among the practitioners.

\section{Moral-ideological dimension}

$\mathrm{H}$ ow, then, is the collective expertise and responsibility of using a new artifact acquired? What seems to hinder the collective mastery of the artifact use? Before turning to these questions, it is essential to look at the interpretations that the former principal scientist of the MEG program gave to problems and to his decision to leave the Institute. This scientist, a pioneer and one of the leading figures in clinical MEG, described the problems in the following way:

\section{Excerpt 11}

There were a couple of things that I feel went wrong here. The first of those (...) in the VA system, it is extremely difficult to advance personnel. So, I had been promised a raise, before I even took the job. (...). Well, four years later they still had not solved that problem. I was working hundred-hour weeks getting, you know, it work out to five dollars an hour or something (laughs). Another issue was (...) my feeling was always that Radiology as a department was happy to have MEG, it was something new and exiting, but there was never any real commitment, if MEG vanished tomorrow, nobody was going to be disappointed. (...) And I didn't like being the underappreciated guest. (...) One other issue... that I didn't like here is that the staff is not my staff. The graduate students like D.J. and E.C., they were my people. I trained them to read MEG, and the dynamics of my relationship with them were very diffe- rent from the dynamics of my relationship with the others who were not chosen by me, so their loyalty and their guidance was very difficult... (Scientist 3)

In the excerpt above, the problems were described in three organizational contexts: in the overall hospital "system" (shortage of resources and personnel), in the radiology department (shortage of commitment and appreciation) and, finally, in the Institute (problems with loyalty/performance of personnel). It can be argued that these issues are typical and obvious problems of the implementation of radically new technologies that have to struggle to get themselves a "place" and the organizations' commitment in already competitive environments (Leonard, 1998).

As excerpt 11 highlights, to be able to get even partial commitment and resources from the organizations, a broker is needed to take the first steps with a new and often unfinished artifact. Typically, it involves a huge amount of individual learning, selfsacrificing work ("hundred-hour weeks") and personal commitment. Oftentimes work with the artifact becomes a life project for the pioneer developers and users of the new technology, and, a matter of complex personal affection and possession of the artifact, co-workers and expertise involved (Latour, 1996; Engeström \& Escalante, 1996). Excerpt 11 interestingly highlights this kind of affectionate and possessive perception toward the endeavor (the words ' $I$ ', 'me' or 'my' appear 12 times in excerpt 11). It can be assumed that affectionate perceptions can also have a negative side in the implementation process by maintaining personified and individualistic strategies toward implementation objectives and implementation related problem solving (e.g., Leonard, 1998; Engeström \& Escalante, 1996).

This question came out also in the inter- 
26

views as hints toward "strong personalities" or "big eagles" involved in MEG. It seemed that the data analysis expertise was something very much unknown among the technologists. It was perceived as something that was kept aside and private by the person involved in the analysis. This kind of individual, solo expertise - accepted as an unwritten rule - was strongly questioned by one of the MEG technologist:

\section{Excerpt 12}

The system should stand on its own merits. Almost anyone should be able to look at it and analyze it and from the data alone - no eagles, no finessing. The answer should be able to come out. It's unfortunate that anyone should suggest that only they can provide the answer from the data. I don't feel that that's objective, and that's clinical or that it's beneficial to the program or the patients or all the people involved. (Technologist 3)

The technologists felt that during the "past era" of the Institute they were not supposed to question things or to be interested in duties other than those given to them. The transition going on at the Institute had made them re-consider this assumption and their own role in the data processing.

\section{Excerpt 13}

Interviewer: Do you like your work this way, or... do you see your work is changing somehow?

Technologist 2: (...) We've been really trying to make us a part. In the past we haven't been as aggressive in the data analysis, and I think sometimes the data that we collected suffered, because: "Why do we have to do it like this?" Nobody would explain why, it didn't make any sense. But when you have an opportunity to see the whole picture, you start understanding: the head must be very still... the head must be in this position... you know on and on and on, and it makes more sense. I just think that the more everybody knows the better exam your patient is gonna have. And we sort of are getting towards that point now...

\section{Excerpt 14}

Interviewer: How do you think... how these current changes have affected to your own work?

Technologist 1: It's forced me for the benefit - and all of our group - to look closer at each case: how we're doing, what we're doing and why we're doing these things. Many, many things that have been done in the past were done that way because we were told this is the way to do it, and that's acceptable, but now there's questions: -"Why are we doing it that way? Is there a better way?" Not saying that that was the wrong way in the first place, but we're just looking at things closer... and I think that has helped actually, because we're all learning still what this machine can, can do for us...

The technologists now seemed to be questioning their uninformed position and advocating participation in sense making activities in the work process ("trying to make us a part"). Going beyond performing work without knowing the purpose of each work action, they wanted to see themselves as subjects getting answers also to the whyquestions. Making sense of the entire process was connected to the quality of particular work actions and reliability of endresults, for instance, digitizing patient's head position indicators prior to measurement. An intention of becoming knowledgeable over the work process indicates emerging collective perspective and collective responsibility, and, respectively, expansion on the moral-ideological dimension of the object.

The constraints of individual expertise and responsibility in data analysis were best illumined in the interview with the neuroscientist and current MEG analyst of the Institute. He faced the time pressure and question of reliability of the results daily when interpreting data for clinical use. For instance, data analysis of functional locations of the brain for a surgical candidate required approximately one 10-hour day per each patient, sometimes even more, depending on the complexity of the case. Although 
aided by a special analysis program, the analysis especially for surgical candidates required intense and time-consuming reading of the signals. ${ }^{7}$ It is not surprising that the problem of individual expertise in data analysis was a major concern of the analyst.

\section{Excerpt 15}

Interviewer: What problems do you have in mind in this current transition process using MEG clinically?

Scientist 1: I guess foremost in my mind are two interrelated problems. One is, that there need to be a number of people trained to use MEG so that when a site comes up or when a site loses somebody, they aren't faced immediately with the... prospect of shutting down and not doing anything because they don't have someone who can interpret data.

The above excerpt shows that the scientist was, first of all, concerned about the small number of people capable of data analysis and clinical interpretation in the current situation where new sites were being established. For him, the training of MEG readers was an urgent issue, as he was considering leaving the facility himself. However, training data analysts as such was not the main problem, but, rather, the question of the content of that training. The lack of shared rules ("the field" mentioned in excerpt 16), among MEG scientists working at different sites, for discriminating between normal and abnormal findings, was of serious concern to the scientist. The current rule of data analysis described by him as "a rule onto himself" (excerpt 16) indicated isolated individual mastery in data analysis and clinical inter-

7 The data analysis in functional brain mapping for surgery requires localizing the sources of the evoked responses, for instance, somatosensory, visual, auditory signals. In some cases, determining the right or the most obvious source location is a complex task. Analysis and location of epileptic seizures requires careful reading of data of the continuous brain activity in order to identify epileptiform brain activity (spikes) from the signals. pretation, and, at the same time, problems in the standardization and broadening of the clinical use of MEG.

\section{Excerpt 16}

The other problem is that the interpretation of the MEG at a clinical level is not at all standardized at this point. There's so few people that each person who does it is kind of a rule onto himself. There's no school out of which all MEGers come, so that there's an accepted belief about how to deal with certain things in the field - there is no field! There are the individuals who do it, and each of those individuals thinks that he does it the best way... and he will instruct the person after him to do it that same way, and, regardless of whether or not that is done accurately, and whether or not the results are good. It's hard to trust that kind of environment. (...) at some point there needs to be created a field where the people who know it stop arguing, get together and say: "we've gotta train people." There're a lot of cutting edge questions what we all argue about, what means what, but we need to decide on some basic center ground, where everybody can say: “- Oh, I think I believe that enough so that we can depend on that in surgery or we can depend on that in epilepsy," and so everybody will do that. So, I think it's a combined problem: there's not enough people and there's consequently not any standardized way of dealing with MEG research or clinical work. (Scientist 1)

Here, the scientist pointed out a crucial question: the reliability ("accuracy", "trust") of the results of the MEG at the clinical level. He advocated a shift in clinical interpretation from isolated individual mastery toward collective expertise through negotiated rules of interpretation, that is, a "basic center ground," among the people involved in analyzing MEG data. He also appealed to the maturity of those people (to "stop arguing") as a condition for collaboration to occur, illustrating the present competitive and constrained relations within the community. The emerging collective responsibility over the clinical reliability of MEG, as perceived by the scientist, indicates expansion in the 
moral-ideological dimension of the object of implementation. The creation of expertise and "best practice" in data analysis should no longer be based on isolated researchers' individual efforts, but, instead, on the joint effort of those involved.

The anticipated expansion of joint work centering around the clinical use of MEG appeared inherently contradictory from the perspective of an individual scientist, who gradually becomes involved in an unknown domain intermixed with diverse interests of the scientific community, medical practices, and the industry. Research work becomes a series of compromises enforced by "realities" such as economical survival.

\section{Excerpt 17}

Scientist 1: This brings up another thought that I keep having about this (...) starting with basic scientist (...) So, the first step, I come to MEG: it looks promising, I do things that those people [who have the money] are interested in. That's just the first compromise, then you start seeing how delicately balanced the survival of MEG is. And so you say to yourself: -"Okay, now I have to make my main research goal, the hypothesis that MEG is clinically useful, and I need to prove that." And that's intermixed into all of the basic science research that I'm interested in doing, and it's hard to distinguish a completely basic science research question from one that's gonna prove that MEG is useful... (...) can you even assure yourself that you're being completely objective about your research... because you're so focused, and your own financial survival is dependent on showing how useful and how meaningful all of this research is that you can no longer say: -"No, this was totally useless for this or that purpose". You can't write that paper, right?

Interviewer: No, you can't do that...

Scientist 1: If I try to write that sentence...my pen blots.

Interviewer: Yes. It's a construction process in a way... you construct that value.

Scientist 1: Yeah, exactly. It was... it was interesting and now I have to prove it's useful too. That's exactly... you construct the value.
Excerpt 17 illustrates the contradiction between the individually perceived rules of independent and objective scientific research and the unwritten rules of the preceding phase of the Institute, presupposed to serve a multiplicity of interests and being economically dependent on the support of the vendor firm. An individual researcher, as a member of the community, becomes engaged in constructing the clinical value of the technology, whether or not he or she is interested in doing that in the first place.

The tensions involved in isolated individual performance on MEG and the responsibility of spreading the user expertise within the community were not restricted to data analysis only. There was only one dedicated neurosurgeon left in the community, in the summer of 1997, engaged in applying and developing the use of MSI in the operations. The transitional, and in various ways contradictory work situation in applying MSI in the operation room was illuminated in the interviews with the MSI nurse and the intraoperative technician. They were the ones who took the imaging workstation to the operation room and operated it during a neurosurgical operation, and in this way provided the actual multi-modality imaging information for the surgeons.

Working in the operation room with neurosurgeons ${ }^{8}$ and nursing staff was a source of distress for the MSI nurse and the technician. Their words, "everybody is fighting for space in OR," show the friction against bringing a new piece of equipment into an already crowded space. Sometimes they were required to compromise and place the

8 Typically, several physicians (at least two assisting surgeons in addition to the main surgeon) operate in a neurosurgical operation such as tumor surgery. In the present setting, the neurosurgeons from the local hospitals formed a surgeon pool, distributing operations among themselves. 
imaging workstation and other equipment in positions that were not optimal for the functioning of the stereotactic camera system. The hierarchical work organization, headed by high-ranking surgeons, was another source of tensions for the team. With the equipment incomprehensible to most of the operation room's staff, they often felt like lowest ranking practitioners and unwanted intruders in the operation room.

\section{Excerpt 18}

Interviewer: What are the typical problems that you have had in the operation room with this workstation?

Technician: I'd say a lack of understanding how the equipment works, and what to do and not to do with it to make it work more efficiently by nursing staff and doctors. People bumping into the camera... (...) then because we're the test site for the software for all of the newest stuff, we've had problems with the software that we have to get around and then report them in and have them fixed then, so... (...) Any time you add another piece of equipment to an already crowded room people get worried that they're not going to be able to work as effectively...

\section{Excerpt 19}

Interviewer: How do you feel about working with the surgeons? Is it easy to work with them?

Nurse: (laughs) It's terrible. (...) There's a... there's often times when ego gets associated, with being a neurosurgeon I think. You don't see that with Doctor B.N., and really you don't see with a lot of people that are here now. One of the surgeons we used to work with, he was pretty hard to get along with. He's a kind of guy that yells at you, throws stuff and things like that, and I think it goes just with the... with the territory, he's egotistical and... you see that.
As the above excerpts show, integrating a new technical artifact and method still at their testing phase to an established work practice can be constrained by problems and hostility of early users unable to understand and to rely on them. The surgeon's yelling and hurling things around, described by the nurse, may be interpreted as a sign of arrogance and impatience associated with the powerful position of the surgeon, or, on the other hand, as a sign of frustration with the technology incomprehensible for the surgeon.

The MSI nurse and the imaging technician were working concretely at the interface between the new technology development and its potential adopter community, the local neurosurgery practice. In a way, they were having a dual object: testing new software for the intraoperative imaging workstation, on the one hand, and assisting surgeons with their operating, on the other. In many cases, these two tasks were successfully performed simultaneously. Due to the complex technology and environment, problems with the technology still at its test phase easily took the main role and became the object of activity for the intraoperative team. This, in turn, did not enhance reliance on the technology by the surgeons and the nursing staff. The transitional situation of the intraoperative team may be summarized with the help of Figure 7, describing the contradictions of the activity system of the team in applying MEG. The lightningshaped two-headed arrow between the rules and the object in Figure 7 illustrates the tension discussed above. 


\section{TOOLS:}

MEG system (MSI), MRI system

Intraoperative imaging workstation (to be taken to OR)

\begin{tabular}{|c|c|c|c|}
\hline $\begin{array}{l}\text { SUBJECT: } \\
\text { Intraoperative team } \\
\text { (MSI nurse, } \\
\text { imaging technician) }\end{array}$ & & $\begin{array}{l}\mathrm{CT}: \longrightarrow \\
\text { g intraoperative } \\
\text { ng system (experiencing } \\
\text { ical problems) and } \\
\text { ing neurosurgeons } \\
\text { operation }\end{array}$ & $\begin{array}{l}\text { OUTCOME: } \\
\text { Improvement of } \\
\text { the technical system } \\
\text { (by identifying problems) } \\
\text { and improvement of } \\
\text { neurosurgical operations }\end{array}$ \\
\hline $\begin{array}{l}\text { RULES: } \\
\text { Rules of occupational } \\
\text { hierarchy in OR: } \\
\text { "Everybody is } \\
\text { fighting for space in OR" } \\
\text { Neurosurgeon culture: } \\
\text { "Ego is associated" }\end{array}$ & $\begin{array}{l}\text { COMMUNITY: } \\
\text { From an individual } \\
\text { neurosurgeon dedicated } \\
\text { to image guided surgery } \\
\text { to all neurosurgeons } \\
\text { at local hospitals }\end{array}$ & $\begin{array}{l}\text { DIVISION OF LABOR: } \\
\text { From close collaboration } \\
\text { the dedicated neurosurge } \\
\text { to collaboration with all } \\
\text { neurosurgeons and OR st }\end{array}$ & with \\
\hline
\end{tabular}

Figure 7. Systemic conditions of the transitional situation of the intraoperative team, responsible for operating the multi-modality imaging workstation in the OR at the Institute in 1997

During the ongoing transition at the Institute, collaboration in the development and application of MEG in neurosurgery rested on a single neurosurgeon, doctor B.N., from the VA hospital. As revealed in the interview with the MSI nurse, one of their common concerns was reliance on the MSI results by the other surgeons in the local hospitals. As shown above, the question of reliability of the end-results of MSI was an ongoing concern for the scientists working closely with data analysis and integration of MEG and MRI information. For the nurse who had several times seen how the results had been actually used in the OR, the question of reliability and reliance was "a matter of confidence over time." Trust was built on long use experience and continuity of use in the operation room.

\section{Excerpt 20}

The MSI nurse: (...) So, clinically there's nice presentation that we give them [to surgeons] so that they don't have to fumble around with all this technical jargon, they don't care about that stuff, they just wanna know: "Can I take this guy's tumor out or not?" I mean that's the bottom line.

Interviewer: Yes. So, how can they be sure that your information is accurate?

The MSI nurse: (laughs) It's a good question. It's... it's a matter of confidence over time, and it's the same thing when we first brought this technology in: you're taking a probe and placing it in someone's brain, and you're telling them where they're at the anatomy, and this gives you numbers of how far off you're supposed to be, but those numbers don't mean anything when it comes down to the surgery. So, it's just a matter of how long they've used it, how many cases they've done with it, and the more they do, they start to trust the information on both the MSI and the System [the intraoperative imaging system], and a certain confidence level is there. (...) Doctor B.N. right now probably has the highest confidence level out of all of them, but he's used it more than anybody else. 
On the other hand, the nurse seemed to be slightly confused with the actual building of that confidence level among the surgeons. As if trying to make sense of the potential dilemma now emerging, he discussed about the surgeons' interconnected difficulties to comprehend the meaning of the technology and to understand and articulate their own expectations about it. At first, he did not consider it as a problem that there was currently only one neurosurgeon in the community who was experienced with and relying on the technology. He saw as important the "personal interest" in the new technology associated with a positive and enthusiastic attitude toward the technology - for building up a confidence on it. The presumption of a personal interest in the adoption of new technology, in his words "specific to every surgeon," posed problems for the creation of collective confidence on the technology, constraining also the standardization of that technology. The reliance on MSI, now personified in a single experienced surgeon, was not in line with the urgent challenge of expanding and sustaining the technology in collective clinical use at the local hospitals. In the interview, the nurse tacitly connected this inherent contradiction with an emerging collective attempt for its possible resolution.

\section{Excerpt 21}

The MSI nurse: Because if they [the surgeons] don't understand that (...) then all they have to do is, is to rely on what you're [referring to himself] doing. It's different whereas if I was to take a plain x-ray machine out to the OR, they all know how it works, they know what to expect, so if they don't get what they expect, then they yell. It doesn't always work that way with us, because they don't always know what to expect. (...) It's really gonna be specific to every surgeon to... Doctor B.N. actually understands this technology very well whereas others don't, it's still too new. Doctor B.N. I think has more of a personal interest in how this type of stuff works whereas the others don't really care.(...) So... That's one of the reasons we're also doing this study right now with the comparison to electrocorticography, because that is known as the 'gold standard', and that will prove that the MSI is a valid way of doing things.

The discourse interestingly highlights an obvious constraint in the activity that maintained the creation of expertise merely as an individual learning process and property. It seemed to presuppose individual, solo responsibility by each user in the process, sometimes isolating those users. Recall the nurse's words, "surgeons...have to rely on what you're doing" (in excerpt 21), referring to himself as the one responsible for the reliability of applying the results in the operating situation. This unwritten rule seemingly originated in the early pioneering phase of the implementation when personal interest in the specific technology may well have been the crucial precondition for the users to start the utilization of the new technology. The situation had changed, however: the community engaged in applying MEG were now challenged to move from the experimental pioneer phase to the phase of sustaining the technology in a particular collective practice, in brain tumor surgery. This new challenge required changing the current conditions and rules of the activity.

In excerpt 21, the nurse proceeded from talking about a positive personal interest in the technology (as compared to "others who don't care"), to introducing a recently started new project. It was a validation study, organized jointly with the Institute and certain collaborators from the local hospitals and aimed at comparing MSI and the known "gold standard", the electrocorticography method, in order to validate, and hopefully also prove, the clinical value of MEG. This can be seen as a tacitly perceived intention to replace the individually experienced reliability and reliance on the technology with a 
collectively experimented reliability through scientific investigation. This newly established project may also be seen as a collectively shared tool, or using Stars (1989) terminology, a boundary object, meant to provide means for building a more collective experience and reliance on the technology. Organizing such a research project indicates expansion of the object of implementation along all the four dimensions of expansion.

As showed in this section, the practitioners connected the constraints of isolated individual mastery of MEG to the entire work process of applying it, starting from the measurement and analysis event at the Institute and proceeding to the operation room at the hospital. As the neuroscientist and the current MEG analyst of the Institute advocated, creation of more collaborative expertise and responsibility should not only mean transferring the individual mastery of the isolated pioneer user to equally isolated other users, but rather, a joint effort of negotiating shared rules of interpretation and validation by those involved. This indicates moral-ideological expansion in the object of implementation and corresponds to the challenge of transitioning from the pioneer phase of the implementation toward more established use of the artifact. However, the desired expansion may require resolving the tensions of the complex organizational context and network, and creation of a shared object of implementation.

\section{Systemic-developmental dimension}

$\mathrm{H}$ ow did the practitioners deal with the future challenges of the organization and the artifact in the interviews? The MEG technologists were simultaneously both hopeful and concerned about the future development at the Institute. They were hoping for leadership and desired the told that they did not know enough about the plans of the new facility director. They were not familiar with the plan to focus the work at the Institute on basic and clinical research. It seemed that their intention of becoming knowledgeable over the development of the work process, as expressed in the interviews, was not recognized in the community. Although aware of the manifold duties of the director in the local medical community, the principal technologist was hoping to involve the director, together with the MEG staff, in the development of the whole MEG process and the technology at the Institute.

\section{Excerpt 22}

Technologist 1: (...) what his [the Director's] ideas are I don't know yet...because he's only been with us a short time and has been really focusing his efforts on the larger clinical application in this division which is the MRI program. But I hope to involve him more heavily in the MEG with all of the basic questions on data collection, first to show him what the questions are, where the errors might be produced... and maybe troubleshoot a better way to do that... and then next: move him into the data analysis and review portion so that he can get a whole picture as to the whole process and help us develop the technology.

The scientists engaged in the data analysis were concerned about finding more clinical applications for MEG in the near future. Although they saw MEG already as a potential clinical tool, for instance, in neurosurgery, they were somewhat concerned about running out of time in creating new applications and surviving financially in the competition with other new imaging technologies. They also stressed the need for a great deal of further research and development work and for comparison of MEG data with other already established methods. A single site could not achieve all that alone. There had not yet been much research col- 
laboration between the sites working with these issues.

The MRI scientist and the collaborating clinicians did not yet perceive MEG as a clinical tool; it was at the research phase, and a great number of studies with normal subjects and with patients were still needed. Ironically, the clinical application they had intensively developed and used so far, the functional brain mapping (MSI), was not considered the "killer application" of MEG. It was the one to start with, while researching simultaneously other options bringing out the true advantage of MEG.

\section{Excerpt 23}

Scientist 1: (...) before it [the MEG] will be useful in the other applications (...) we need to spend a lot of basic research time finding out what normals look like. A small amount of that has been done, but a tremendous amount more needs to be done, and the data needs to come to the same level that EEG has been at for great many years before we can really use it to evaluate other types of diseases.

\section{Excerpt 24}

Scientist 2: I think there are applications where MEG will be the clinical modality of choice. I don't see that the basic functional mapping - applications that we spend a lot of time doing - will be that application. (...) my opinion is that epilepsy applications will be the killer out for getting MEG standard established. You really have to take into account the timing advantage of MEG. (...) epilepsy, which really involves the timing, to a large extent really highlights that advantage whereas in somatomotor, you don't use the timing at all (...) so the clinical applications must use that strength of timing. (...) I definitely believe MEG will survive, but as a routine clinical tool, I think it has a long way to go.

The main collaborating neurosurgeon and the neurologist engaged in the validation study addressed the clinical potential and advantages of MEG in solving particular ongoing problems of their medical practice. For the neurosurgeon's point of view, MSI was already able to provide important information for planning a surgical approach in a neurosurgery operation. In difficult tumor cases, surgeons usually used invasive electrocorticography (EcoG) prior to the actual surgery, in order to identify the eloquent cortex in relation to the tumor. Sometimes the electrodes (grids) for cortical stimulation, placed on the surface of the brain, did not work properly, or, the size of the hole opened on the scull restricted the proper placing of the grids. A possibility of avoiding these additional invasive preoperative evaluations on patients with the MSI was seen as an important advantage.

\section{Excerpt 25}

Clinician 1: What you saw in the last corticography is a classic example of why corticography is needed. Neurosurgeon oftentimes determines visually where the motor cortex is. And sometimes it is very difficult because the tumor can alter the anatomy of the brain, so what one thinks is the motor strip, is not.

\section{Excerpt 26}

Neurosurgeon: The problem is that with the corticography, you get one shot with the patient, you take patient to the operating room, you are opening up the scull ... We recently had a case where there was a failure of the grids, they were not recording properly and you had no localizing information. With the MSI, you get it all preoperatively, so if it does not work at the one time you can go back and repeat it and get it right before you go to the operating room. That is a huge advantage. And also the EcoG makes you do all your decision making intraoperatively. Anything that can be done preoperatively can be taking into account to plan the surgical approach, to inform the patient about the risks, how high or low they may be, and to guide both the surgeon and the patient to make the choices of operation.

The collaborating neurologist addressed the potential of MSI in localizing non-invasively epilepsy seizures, although there remained many unknown questions in it. He 
advocated further research on the capabilities and limitations of MEG in regard to epilepsy before applying the information to full scale clinical work. He was currently conducting research on the topic at the University of New Mexico. He was also an expert of clinical neurophysiology procedures in the validation study aimed at comparing the information acquired from MSI with the recognized, accepted "gold standard" (EcoG). The information was considered important for the standardization of the application, since there hasn't been direct head-to-head comparison between MEG and EcoG.

The collaborating neurosurgeon - already an actual user of the technology - saw the future development and use of MEG in optimistic terms. He was already content with the level of accuracy provided by MSI when used in actual operating.

\section{Excerpt 27}

The current state of MSI makes it extremely useful for sensory cortex localization and it does that, what we feel, with the level of accuracy that exceeds EcoG. (...) MSI can localize these cortical regions in true three dimensional space whereas corticography is really a two dimensional recording across the surface of the brain. And it therefore, in my opinion, is the most accurate way to localize sensory cortex presently. Use and evolution of image guided surgical navigation techniques has made this kind of technology- it is a natural marriage to put those two technologies together (...) (Neurosurgeon)

Interestingly enough, the neurosurgeon recognized the challenges for collaboration in the complex organizational setting currently involved in the validation study. He was aware of some of the ongoing organizational transitions at the Institute. Yet he believed that "users with great demand" and "a business attitude" towards the endeavor will eventually be the key in solving the problems of the complex organization.

\section{Excerpt 28}

We are a very complicated organization, because the unit referring to the Institute] is housed in a government owned hospital and the neuroimaging group exists as a separate entity outside of this government hospital (...) It takes a fair amount of co-operation to get all that set up. The network will become even more complicated over time as we start not only to become familiar with this technology but to rely on it, when it becomes a standard way to do neurosurgical procedures. (...) If there are users with great demand, everyone will be well motivated to work things out, and these things do work out. Everybody understands how business goes and that we have to do business, and then we'll do it. (Neurosurgeon)

The situation of the neurosurgeon as an enduser of multi-modality imaging techniques may be summarized with the help of Figure 8 , depicting the unarticulated contradiction of the activity of sustaining and expanding MEG in neurosurgery.

If compared to the transitional conditions of the other practitioners in the process of functional brain mapping for neurosurgery, this particular surgeon did not suffer from such concerns and uncertainties that were expressed by the technologists and the scientists. He needed reliable and timely functional brain mapping information for operations and he saw no particular problems in acquiring them. He represented a lead user (von Hippel, 1988), a user with great demand, and also a strategically important powerful boundary spanner (e.g., Leonard, 1998) between organizations. He brought the customer perspective to the process, interested in one application of the technology. He seemed to believe in rational behavior of the actors, tacitly assuming that all participants in the endeavor have a similar vision and a shared object of activity, as well as equal possibilities to acquire knowledge and expertise on the process. As shown in this paper, the assumption that transition ap- 
outlines-2000.qxd 23-11-00 12:55 Side 35

TOOLS:

Multi-modality imaging techniques (e.g., MSI)

for preoperative planning etc.

A validation study (to prove the clinical usefulness)

\begin{tabular}{|c|c|c|c|}
\hline $\begin{array}{l}\text { SUBJECT: } \\
\text { Neurosurgeon, } \\
\text { representing a lead user } \\
\text { (with personal interest } \\
\text { and need) }\end{array}$ & & $\begin{array}{l}\text { JJECT: } \\
\text { eoperative decision } \\
\text { king and } \\
\text { age guided surgery }\end{array}$ & $\begin{array}{l}\text { OUTCOME: } \\
\text { Safer operations } \\
\text { and decrease of } \\
\text { invasive preoperative } \\
\text { studies on patients } \\
\text {-"the use of MSI as a } \\
\text { standard procedure" }\end{array}$ \\
\hline $\begin{array}{l}\text { RULES: } \\
\text { From personal interest } \\
\text { and experience to } \\
\text { rules of clinical validation } \\
\text { of new diagnostic } \\
\text { technologies }\end{array}$ & $\begin{array}{l}\text { COMMUNITY: } \\
\text { Local surgeon } \\
\text { community unwilling } \\
\text { to use new technology } \\
\text { - until the clinical value } \\
\text { gets proved }\end{array}$ & $\begin{array}{l}\text { DIVISION OF LA } \\
\text { From complex loca } \\
\text { organization with d } \\
\text { priorities to shared } \\
\text { that will resolve the } \\
\text { in setting up the val } \\
\text { study and full scale }\end{array}$ & $\begin{array}{l}\text { BOR: } \\
\text { l work } \\
\text { iffering } \\
\text { "business attitude" } \\
\text { complexity } \\
\text { idation } \\
\text { service }\end{array}$ \\
\hline
\end{tabular}

Figure 8. Systemic conditions of the transitional situation of the neurosurgeon collaborating with the Institute, in 1997

pears the same to everybody even within a single organization is very problematic. The lighting-shaped two-headed arrow between the object and the community in Figure 8 describes this potential constraint in the future resolution of differing priorities and objects within and between activity systems.

To sum up, the practitioners were capable of considering the artifact and its future applications reflectively and in developmental terms, also interpreting the possible alternatives of development in a broader frame of imaging modalities. Though they were concerned or slightly worried about the future, they were not paralyzed with the uncertain situation. Interestingly enough, not only the main collaborating neurosurgeon - as a customer - but also the technologists working on the laboratory shop floor expressed motivation and commitment to developing further the work with the artifact at the Institute. It seemed that the practitioners had no choice: they had to take responsibility over the future development and application work due to the long distance to the original developer company. However, the concerns and commitments were not shared among practitioner groups. At this point, the object of implementation seemed to be shared only in the imagination of various practitioners.

\section{Conclusions}

I $\mathrm{n}$ this paper, I have analyzed the implementation of a hybrid artifact - the neuromagnetometer device - from the viewpoint of one user organization, the New Mexico Institute of Neuroimaging, during the period in which it was facing a challenge of moving from the introductory phase of the implementation toward the more established adoption into clinical use. The analysis shows that the anticipated transformation of the artifact, through trials of implementation 
and adoption, constituted a major challenge also for the Institute and its practitioners.

I applied the concept of expansion in the analysis of interview data and found that the perceptions of the practitioner groups involved in the implementation indicate expansion of the object of implementation along the social-spatial, anticipatory-temporal, moral-ideological, and systemic-developmental dimensions of expansion. The perceptions of the participants about the transitional process at the Institute and the related network are summarized in Table 2. Perceptions of the same type are combined and categorized according to the four expansive dimensions of the object and the three levels of organizational context relevant to the transition.

Table 2 illustrates the multi-voiced character of implementation, consisting of heterogeneous occupational groups and different organizational contexts. The local community involved in applying MEG consisted of several loosely coupled activity systems with different objects and tools, as well as different places and schedules of work. Each practitioner group seemed to have a specific and partial point of view, and different kinds of concerns toward the transition. However, among all practitioner groups, and along all four dimensions of expansion, especially one common concern and contradiction continued showing up in the data. This was the tension between isolated individual expertise and responsibility in applying MEG and the simultaneous challenge to establish the use of MEG in preoperative planning of neurosurgical patients.

The findings concerning the expansions shed new light on the role of an individual product champion as the main agent in successful adoption (Maidique, 1980). The di- mensions of expansion applied here revealed the obvious need - and also the various constraints - of transferring individual expertise to a user collective. The findings of the present case study did not indicate a next user-champion to be the main agent to achieve this transition.

The social-spatial dimension of expansion not only indicated requirements for continuous integration of different technologies, but also an intention by the practitioners to enlarge the functional and spatial scope of work. This integration of separate work practices into a shared work process presupposes collective action, negotiating a common ground for the emerging new phase of implementation. The anticipatorytemporal dimension revealed a desire to broaden the temporal trajectories of implementation. Transitioning from an introductory phase toward the consolidation phase of implementation enlarges the trajectory to include also the continuity and reproducibility of results. Maintaining these within a complex organizational context will require a collective subject, a recognized collaborative structure, as responsible for the endeavor. The moral-ideological dimension showed an urgent need to spread and share the isolated, individual application expertise within the wider user community. This will require negotiated rules of clinical interpretation and decision-making as well as more basic research work for understanding the advantages and limitations of the application. Finally, the systemic-developmental dimension lends support to the idea of a collective subject as a motor for anticipated transition. All practitioners - not only the high-ranking specialists - showed commitment to and responsibility for future development of the application and the technology. 


\begin{tabular}{|c|c|c|c|c|}
\hline & $\begin{array}{l}\text { Social-spatial dimen- } \\
\text { sion }\end{array}$ & $\begin{array}{l}\text { Anticipatory-tempo- } \\
\text { ral dimension }\end{array}$ & $\begin{array}{l}\text { Moral-ideological di- } \\
\text { mension }\end{array}$ & $\begin{array}{l}\text { Systemic-developmen- } \\
\text { tal dimension }\end{array}$ \\
\hline $\begin{array}{l}\text { Organization } \\
\text { (the Institute) }\end{array}$ & $\begin{array}{l}\text { A need to expand tech- } \\
\text { nologists' work objec- } \\
\text { tive from measure- } \\
\text { ments only to data } \\
\text { analysis (tech 1, tech 2, } \\
\text { tech 3) } \\
\text { Technology integration, } \\
\text { display and use of the } \\
\text { data in surgical opera- } \\
\text { tions needed to be fur- } \\
\text { ther developed (scien- } \\
\text { tist 2) }\end{array}$ & $\begin{array}{l}\text { From largely unrepeat- } \\
\text { able, non-documented } \\
\text { and un-timely work to- } \\
\text { ward more repro- } \\
\text { ducible, accurate, time- } \\
\text { ly and documented } \\
\text { work (tech 1, tech 2, } \\
\text { tech 3) } \\
\text { From "industry-orient- } \\
\text { ed approach" toward } \\
\text { more "long-term scien- } \\
\text { tific approach" (scien- } \\
\text { tist 1, scientist 2, clini- } \\
\text { cian 2) }\end{array}$ & $\begin{array}{l}\text { From individual mas- } \\
\text { tery of MEG toward } \\
\text { shared competence and } \\
\text { responsibility (tech } 1 \text {, } \\
\text { tech } 2 \text {, tech } 3 \text { ) }\end{array}$ & $\begin{array}{l}\text { Expecting the director } \\
\text { to "help us to develop } \\
\text { the technology" } \\
\text { (tech 1) } \\
\text { Expecting leadership } \\
\text { and vision to start fo- } \\
\text { cusing on clinical ser- } \\
\text { vice (tech 2, tech 3) }\end{array}$ \\
\hline $\begin{array}{l}\text { Local customer } \\
\text { and partner } \\
\text { institutions } \\
\text { (local hospitals } \\
\text { and departments) }\end{array}$ & $\begin{array}{l}\text { A need to (re)establish } \\
\text { collaboration with hos- } \\
\text { pital clinicians to } \\
\text { "identify relevant ques- } \\
\text { tions for MEG" (tech 1, } \\
\text { tech 2) } \\
\text { A need to involve OR } \\
\text { staff to understand the } \\
\text { use of the intraopera- } \\
\text { tive system (technician, } \\
\text { nurse) } \\
\text { A need of the Institute } \\
\text { to establish research } \\
\text { collaboration and focus } \\
\text { on local patient popula- } \\
\text { tions (scientist 3) }\end{array}$ & $\begin{array}{l}\text { Joint effort, a validation } \\
\text { program, needed to } \\
\text { demonstrate the clinical } \\
\text { potential and value of } \\
\text { MEG ( clinician 1) } \\
\text { Emerging "users with } \\
\text { great demand" and } \\
\text { "business attitude" will } \\
\text { resolve the problems of } \\
\text { a "complex user orga- } \\
\text { nization" (neurosur- } \\
\text { geon) }\end{array}$ & $\begin{array}{l}\text { From individually } \\
\text { emerging "trust" to- } \\
\text { ward experimented re- } \\
\text { liability (validation } \\
\text { program) (nurse) } \\
\text { Problem of "construct- } \\
\text { ed value" of technolo- } \\
\text { gy (scientist } 1 \text { ) }\end{array}$ & $\begin{array}{l}\text { Development of the } \\
\text { MEG program will be- } \\
\text { come critical to the use } \\
\text { of neurosurgical appli- } \\
\text { cation (nurse) } \\
\text { Other hospitals in the } \\
\text { area will become in- } \\
\text { volved using MSI in } \\
\text { neurosurgical opera- } \\
\text { tions in the future (neu- } \\
\text { rosurgeon) }\end{array}$ \\
\hline $\begin{array}{l}\text { Network/scienti- } \\
\text { fic community } \\
\text { (technology sup- } \\
\text { pliers, other user } \\
\text { sites and institu- } \\
\text { tions) }\end{array}$ & $\begin{array}{l}\text { A need for collabora- } \\
\text { tion between MEG } \\
\text { sites, information shar- } \\
\text { ing etc. (tech 1, tech 2, } \\
\text { scientist 1) } \\
\text { Collaboration between } \\
\text { MEG sites not neces- } \\
\text { sary at the moment } \\
\text { (scientist } 3 \text { ) } \\
\text { A need to move from } \\
\text { "subjective interpreta- } \\
\text { tion" toward more au- } \\
\text { tomated" data analysis } \\
\text { (scientist 2) }\end{array}$ & $\begin{array}{l}\text { A need for more time } \\
\text { for MEG to become fi- } \\
\text { nancially viable and to } \\
\text { survive in the competi- } \\
\text { tion (scientist } 3 \text { ) } \\
\text { Increasing number of } \\
\text { MEG sites need urgent- } \\
\text { ly more training and } \\
\text { qualified personnel } \\
\text { (scientist 1, scientist 3) }\end{array}$ & $\begin{array}{l}\text { From individually mas- } \\
\text { tered work toward } \\
\text { shared rules, a "field" } \\
\text { (scientist 1, clinician 2) } \\
\text { MEG supplier should } \\
\text { lead the work of tech- } \\
\text { nical problem solving } \\
\text { at the sites (scientist 2, } \\
\text { scientist } 3 \text { ) } \\
\text { A need for division of } \\
\text { research objectives be- } \\
\text { tween sites (scientist 2, } \\
\text { scientist } 3 \text { ) }\end{array}$ & $\begin{array}{l}\text { A need to find more } \\
\text { clinical applications for } \\
\text { MEG to survive in the } \\
\text { competition (scientist } \\
\text { 1, scientist 3) } \\
\text { MEG still needs R\&D } \\
\text { before becoming a clin- } \\
\text { ical tool (clinician 1, } \\
\text { scientist 2) } \\
\text { MEG will be useful } \\
\text { and when its clinical } \\
\text { value is approved, its } \\
\text { use will spread (neuro- } \\
\text { surgeon) }\end{array}$ \\
\hline
\end{tabular}

Table 2. Perceptions of participants about the transitional process of the Institute and related network (the shortened term "tech" stands for technologist) 
38

These results suggest that the major contradiction - between the emerging new object of implementation and the prevailing rules and division of labor causing the isolated user expertise to continue at the Institute can not be understood only in terms of mutual adaptation of the technology and user environment. It can be understood as signaling for a need and an opportunity for expansion. Expansion revealed in the present case was, primarily, emergence of a new, potentially shared object of activity within and between practitioner groups. Expansion of the object involves the practitioners to recognize the different objects and requirements of the pioneer phase of the implementation on the one hand, and the new phase of establishing the application to medical practice on the other hand. The capability to understand the significance of the current transition and to make the difference between the two phases of implementation, in other words, the ability to make expansive distinctions, was emerging among the practitioners.

Transition enables and requires this capability also in the creation of new tools, rules, and division of labor within the Institute's activity system. In this respect, local transition drives further integration and development of the imaging technologies and other systems, including MEG. As showed in the present analysis, expansion needs to include all elements of the activity system. In the adoption of radically new technologies, mutual adaptation and conformation of the technology and user organization are not enough. The artifact as a merely fixed "thing" into which users adapt should be questioned. Hence, user activity should not be seen as something given or predetermined. Rather, adoption into use involves the user activity to expand along the four dimensions suggested here. However, this constitutes a major learning challenge for the user organization involved.
A crucial challenge of the Institute was related to the need for collective expertise and responsibility in the emerging new phase of the implementation. The new validation project indicated movement toward this direction. This project was a potential shared tool among the practitioner groups. However, the meaning of this endeavor as an expansive tool and possibility was not yet fully recognized within the community. It seemed also that all practitioner groups did not have the same access to the information about the new plans.

The emerging new object, the endeavor to establish the use of the artifact in neurosurgical practice, may remain only partially shared if not made visible by deliberate effort among practitioners. The findings of this case analysis about the partial and separate perceived objects of implementation among the practitioners do not support the idea of invisibility as a desired objective for implementation, suggested by Leonard-Barton and Kraus (1985). The blind men need shared tools to perceive the elephant. Smooth, invisible "hand-off" to end-users is a problematic ideal that can hardly be achieved in real life.

What needed to happen in the case of the Institute and in similar cases of implementing complex new technology? The isolated or partial perspectives of the practitioners in the critical phase of implementation can be seen as an opportunity for expansion. The results suggest that expansion requires collective visualization of work and reflective dialogue on it among the practitioner groups. In order to start creating mutual understanding, practitioners and different sub-groups can be encouraged to consciously analyze, represent and communicate their perspectives to each other. It is shown however, that this kind of metacommunicative action is difficult to achieve spontaneously and maintain coherent within hazardous work situa- 
tions (Hasu, 2000; Hasu \& Engeström, 2000).

Activity-theoretical concepts and methods have been employed experimentally to overcome such problems. Intervention methods for collective visualization of work and shared meta-tools for dialogical diagnosis, problem solving and work redesign at actual work settings are recently being developed and tested (e.g. Engeström, 1999). The future challenge for the present research will be both further developing these analytical tools and analyzing their value for the organizations implementing new technology.

\section{References}

Adler, P. S., Riggs, H. E. \& Wheelwright, S. C. 1989. Product development know-how: Trading tactics for strategy. Sloan Management Review, 31, 7-17.

Barley, S.R. 1986. Technology as an occasion for structuring: Evidence from observations of CT Scanners and the social order of radiology departments. Administrative Science Quarterly, 31, 78-108.

Billig, M., Condor, S., Edwards, D., Gane, M., Middleton, D. \& Radley, A. 1988. Ideological dilemmas: A social psychology of everyday thinking. London: Sage.

Blackler, F., Crump, D. \& McDonald, S. 1999. Managing experts and competing through innovation: An activity theoretical analysis. Organization, 6, 5-31.

Biemans, W. G. 1992. Managing innovation within networks. London: Routledge.

Blume, S. 1992. Insight and industry. On the dynamics of technological change in medicine. Cambridge: The MIT Press.

Burgelman, R.A. \& Maidique, M. A. (1988). Strategic management of technology and innovation. Illinois: Irwin, Inc.

del Campo, A. A., Sparks, A. Hill, R. C. \& Keller, R. T. 1999. The transfer and commercialization of university-developed medical imaging technology: Opportunities and problems. IEEE Transactions of Engineering
Management. International Research Journal on Management of Engineering and Technology, 46, 289-298.

Cole, M. \& Engeström, Y. 1993. A cultural-historical approach to distributed cognition. In G. Salomon (Ed.), Distributed cognitions: Psychological and educational considerations. Pp. 1-46. Cambridge: Cambridge University Press.

Clarke, A.E. \& Gerson, E.M. 1990. Symbolic interactionism in social studies of science. In H. S. Becker \& M. M. McCall (Eds.), Symbolic interaction and cultural studies. Pp. 179-214. Chicago: The University of Chicago Press.

Coombs, R., Richards, A., Saviotti, P.P. \& Walsh, V. 1996. Technological collaboration. The dynamics of cooperation in industrial innovation. Cheltenham, UK: Edward Elgar.

Engeström, Y. 1987. Learning by expanding: An activity-theoretical approach to developmental research. Helsinki: Orienta-Konsultit.

Engeström, Y. 1990. Learning, working and imagining: Twelve studies in activity theory. Helsinki: Orienta-Konsultit.

Engeström, Y. 1996. The tensions of judging: Handling cases of driving under the influence of alcohol in Finland and California. In Y. Engeström \& D. Middleton (Eds.), Cognition and communication at work. Pp. 199-232. Cambridge: Cambridge University Press.

Engeström, Y. 1999. Expansive visibilization of work: An activity-theoretical perspective. Computer-Supported Cooperative Work, 8, 63-93.

Engeström, Y. 2000. Making expansive decisions. An activity-theoretical study of practitioners building collaborative medical care for children. In C. M. Allwood \& M. Selart (Eds.), Decision making: Social and creative dimensions. Dordrecht: Kluwer (in press).

Engeström, Y. \& Escalante, V. 1996. Mundane tool or object of affection? The rise and fall of Postal Buddy. In B. Nardi (Ed.), Activity theory and human-computer interaction. Pp. 325-373. Cambridge: The MIT Press.

Engeström, Y., Miettinen, R. \& Punamäki, R-L. (Eds.), 1998. Perspectives on activity theory. Cambridge: Cambridge University Press. 
(Eds.), The positive sum strategy: Harnessing

Engeström, Y., Engeström, R. \& Vähäaho, T. 1999. When the center does not hold: The importance of knotworking. In S. Chaiklin, M. Hedegaard \& U. J. Jensen (Eds.), Activity theory and social practice: Cultural-historical approaches. Pp. 345-374. Aarhus: Aarhus University Press.

Fincham, R., Fleck, J., Proctor, R., Scarborough, H., Tierney, M. \& Williams. R. 1995. Implementation and innovation. Pp. 189-208. In Expertise and Innovation: Information technology strategies in the financial services sector. Oxford: Oxford University Press.

Fleck, J. 1994. Learning by trying: The implementation of configurational technology. Research Policy, 23, 637-652.

Fujimura, J. H. 1996. Crafting science. A sociohistory of the quest for the genetics of cancer. Cambridge: Harvard University Press.

Green, K. 1992. Creating demand for biotechnology: Shaping technologies and markets. In R. Coombs, P. Saviotti \& V. Walsh (Eds.), Technological change and company strategies. Pp. 164-184. London: Academic Press.

Hasu, 1999. Neuromag-aivotutkimuslaite - fysiikan laboratoriosta sairaalakäyttöön. In R. Miettinen, J. Lehenkari, M. Hasu \& J. Hyvönen, Osaaminen ja uuden luominen innovaatioverkoissa. Pp. 89-116. Sitra 226. Vantaa: Taloustieto Oy. (In Finnish).

Hasu, M. 2000. Constructing clinical use. An activity-theoretical perspective on implementing new technology. Technology Analysis and Strategic Management, 12 (3), 369-382.

Hasu, M. \& Engeström, Y. 2000. Measurement in action. An activity-theoretical perspective on producer-user interaction. International Journal of Human-Computer Studies, 53 (1), 61-89.

von Hippel, E. 1988. The sources of innovation. New York: University Press.

von Hippel, E. \& Tyre, M. 1995. How learning by doing is done: Problem identification in novel process equipment. Research Policy, 24, 1-12.

von Hippel, E., Thomke, S. \& Sonnack, M. 1999. Creating breakthroughs at 3M. Harvard Business Review, Sep.-Oct., 3-9.

Kline, S.J. \& Rosenberg, N. 1986. An overview of innovation. In R. Landau \& N. Rosenberg, technology for economic growth. Pp. 275305. Washington DC: National Academy Press.

Koschmann, T., Kuutti, K. \& Hickman, L. 1998. The concept of breakdown in Heidegger, Leont'ev, and Dewey and its implications for education. Mind, Culture and Activity, 5, 2541.

Latour, B. (1996). Aramis or the love of technology. Cambridge: Harvard University Press.

Lave, J. \& Wenger, E. 1991. Situated learning: Legitimate peripheral participation. Cambridge: Cambridge University Press.

Leont'ev, A.N. 1978. Activity, consciousness, and personality. Englewood Cliffs: PrenticeHall.

Leonard, D. 1998. Wellsprings of knowledge. Building and sustaining the sources of innovation. Boston: Harvard Business School Press. (First published in 1995)

Leonard-Barton, D. \& Kraus, W.A. 1985. Implementing new technology. Harvard Business Review, Nov.-Dec., 102-110.

Lundvall, B-Å. 1992. User-producer relationships, national systems of innovation and internalisation. In B- $\AA$ Lundvall (Ed.), National systems of innovation. Towards a theory of innovation and interactive learning. Pp. 45-67. London: Pinter Publishers.

Maidique, M. A. 1980. Entrepreneurs, champions and technological innovation. Sloan Management Review, 21, (2), 59-76.

Marton, F. 1981. Phenomenography - describing conceptions of the world around us. Instructional Science, 10, 177-200.

Miettinen, R. \& Hasu, M. 2000. Articulating user needs in collaborative design. Towards an activity-theoretical approach. Forthcoming in Computer-Supported Cooperative Work.

Preece, D. A. 1989. Managing the adoption of new technology. London: Routledge.

Rogers, E. M. 1983. Diffusion of innovations. Third edition. London: The Free Press.

Rothwell, R. 1994. Industrial innovation: Success, strategy, trends. In M. Dodgson \& R. Rothwell (Eds.) The handbook of industrial innovation. Pp. 33-53. London: Edward Elgar. 
Shaw, B. 1985. The role of the interaction between the user and the manufacturer in medical equipment innovation. $R \& D$ Management, 15, 283-292.

Shaw, B. 1994. User/supplier links and innovation. In M. Dodgson \& R. Rothwell (Eds.), The handbook of industrial innovation. Pp. 275-284. London: Edward Elgar.

Star, S. L. 1989. The structure of ill-structured solutions: Boundary objects and heterogeneous distributed problem solving. In L. Gasser \& M. N. Huhns (Eds.) Readings in distributed artificial intelligence. Vol. 3. Pp. 37-54. Menlo Park: Morgan Kaufmann.

Timmermans, S. \& Berg, M. 1997. Standardization in action: Achieving universalism and localization in medical protocols. Social Studies of Science, 27, 273-305.

Voss, C.A. 1994. Implementation of manufacturing innovations. In M. Dodgson \& R. Rothwell (Eds.), The handbook of industrial innovation. Pp. 405- 417. Cheltenham, UK: Edward Elgar. 